\title{
Laboratory Studies of Volcanic Jets
}

\author{
SUSAN WERNER KIEFFER \\ U.S. Geological Survey, Flagstaff, Arizona \\ BRADFORD STURTEVANT \\ California Institute of Technology, Pasadena
}

\begin{abstract}
The study of the fluid dynamics of violent volcanic eruptions by laboratory experiment is described, and the important fuid-dynamic processes that can be examined in laboratory models are discussed in detail. In preliminary experiments, pure gases are erupted from small reservoirs. The gases used are Freon 12 and Freon 22, two gases of high molecular weight and high density that are good analogs of heavy and particulate-laden volcanic gases; nitrogen, a moderate molecular weight, moderate density gas for which the thermodynamic properties are well known; and helium, a low molecular weight, lowdensity gas that is used as a basis for comparison with the behavior of the heavier gases and as an analog of steam, the gas that dominates many volcanic eruptions. Transient jets erupt from the reservoir into the laboratory upon rupture of a thin diaphragm at the exit of a convergent nozzle. The gas accelerates from rest in the reservoir to high velocity in the jet. Reservoir pressures and geometries are such that the fluid velocity in the jets is initially supersonic and later decays to subsonic. The measured reservoir pressure decreases as the fluid expands through repetitively reflecting rarefaction waves, but for the conditions of these experiments, a simple steady-discharge model is sufficient to explain the pressure decay and to predict the duration of the flow. Density variations in the flow field have been visualized with schlieren and shadowgraph photography. The observed structure of the jet is correlated with the measured pressure history. The starting vortex generated when the diaphragm ruptures becomes the head of the jet. Though the exit velocity is sonic, the flow head in the helium jet decelerates to about one-third of sonic velocity in the first few nozzle diameters, the nitrogen head decelerates to about three-fourths of sonic velocity, while Freon maintains nearly sonic velocity. The impulsive acceleration of reservoir fluid into the surrounding atmosphere produces a compression wave. The strength of this wave depends primarily on the sound speed of the fluid in the reservoir but also, secondarily with opposite effect, on the density: helium produces a relatively strong atmospheric shock while the Freons do not produce any optically observable wave front. Well-formed $\mathbf{N}$ waves are detected with a microphone far from the reservoir. Barrel shocks, Mach disks, and other familiar features of steady underexpanded supersonic jets form inside the jet almost immediately after passage of the flow head. These features are maintained until the pressure in the reservoir decays to sonic conditions. At low pressures the jets are relatively structureless. Gas-particle jets from volcanic eruptions may behave as pseudogases if particle concentrations and mass and momentum exchange between the components are sufficiently small. The sound speed of volcanic pseudogases can be as large as $1000 \mathrm{~m} \mathrm{~s}^{-1}$ or as small as a few tens of meters per second depending on the mass loading and initial temperature. Fluids of high sound speed produce stronger atmospheric shock waves than do those of low sound speed. Therefore eruption of a hot gas lightly laden with particulates should produce a stronger shock than eruption of a cooler or heavily laden fluid. An empirical expression suggests that the initial velocity of the head of supersonic volcanic jets is controlled by the sound speed and the ratio of the density of the erupting fluid to that of the atmosphere. The duration of gas or pseudogas eruptions is controlled by the sound speed of the fluid and the ratio of reservoir volume to vent area.
\end{abstract}

\section{INTRODUCTION}

During violent volcanic eruptions, magma transforms from a liquid containing dissolved gases into a fragment-laden gas (magmatic eruptions); liquid water within pores and cracks transforms into steam laden with crushed host rock (phreatic eruptions); and/or magma and external water may interact (phreatomagmatic eruptions). The thermodynamic and fluiddynamic behavior of complex fluids expanding through regions of complex geometry within the volcano and into the surrounding atmosphere is not well understood and is not amenable to direct observation. Transformation of magma or liquid water plus surrounding rock into a particulate-laden gas, acceleration and motion of this gas, and its interaction with the surrounding atmosphere in a jetlike flow involve the transport of mass, momentum, and energy by complex and nonlinear mechanisms. It is important that these processes be

This paper is not subject to U.S. copyright. Published in 1984 by the American Geophysical Union.

Paper number 4B0362. studied experimentally so that key parameters can be varied in a controlled fashion, because reliable models for volcanic eruptions and their hazards can be formulated only if the fundamental dynamic processes that govern the behavior of volcanic jets are understood. Therefore in the laboratory we abstract the governing physics from the field situation insofar as is possible without altering the essential features of the flow. Because our laboratory experiments are of small scale compared with volcanic systems (by a factor of from $10^{-5}$ to $10^{-7}$ ), it is not possible to model simultaneously the effects of fluid inertia and gravity on the flowing fluid. On the other hand, the effects of complex geometry, both within the volcanoes and in the surrounding topography, can be studied at reduced scale.

Several workers [Shoemaker et al., 1962; Bennett, 1971, 1974; McGetchin and Ulrich, 1973] have suggested that fluid flow during large gas-rich volcanic eruptions resembles the flow from laboratory shock tubes, one-dimensional devices in which a high-pressure gas at one end is separated from a low-pressure chamber at the other by a diaphragm that rup- 


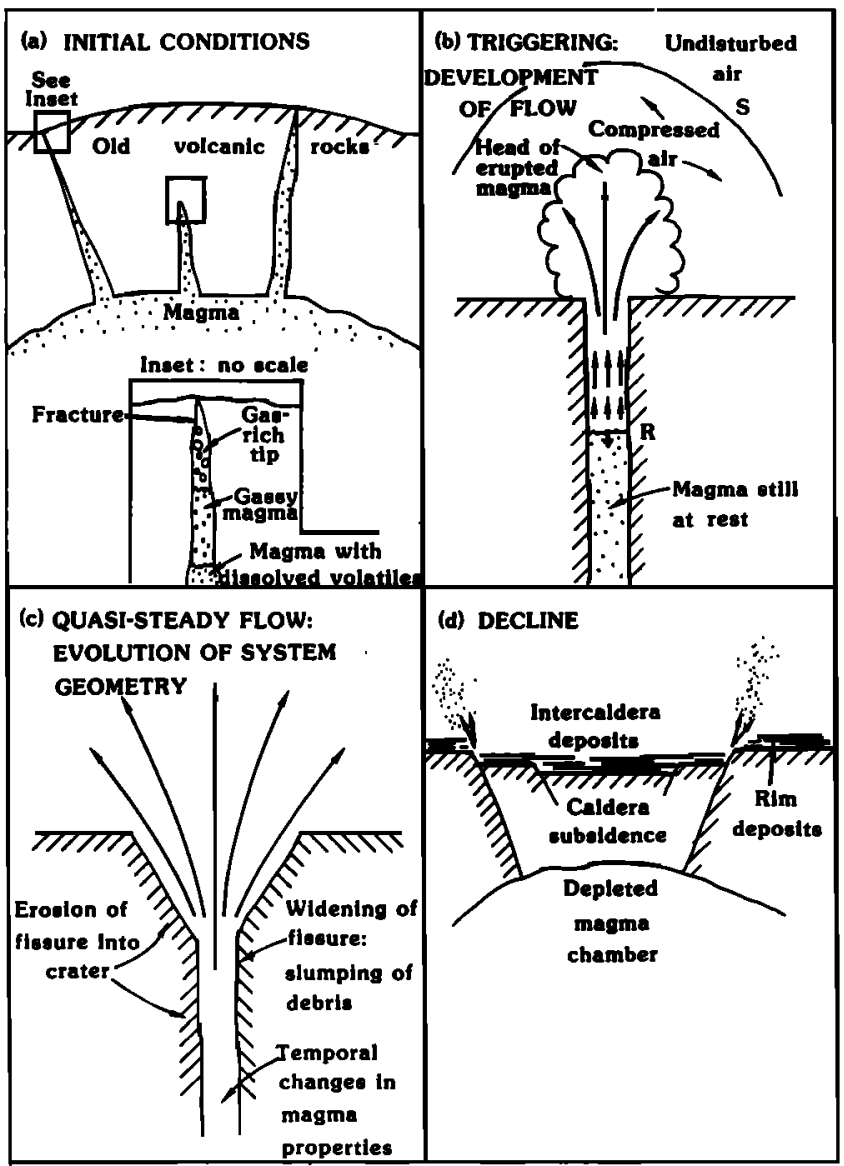

Fig. 1. Schematic diagram indicating stages of a gas-rich eruption (such as an eruption from a caldera or a stratovolcano) in relation to the fluid flow processes. (a) Initial conditions: intrusion of magma into the near-surface environment and propagation of a conduit (fracture) to the surface just prior to magma eruption. (b) Triggering and development of flow: exposure of the magma to the ambient atmosphere, propagation of a compression wave into the atmosphere in response to the eruption of the fluid, rise of material in the fracture, continued development of the fracture vertically and laterally. (c) Quasi-steady flow: development of the flow behind the unsteady front, emptying of the bulk of the magma reservoir, evolution of system geometry and magma properties; episodes of unsteady flow may occur. (d) Decline of flow: formation of caldera. Processes may overlap stages.

tures to initiate the flow. In our laboratory work we have examined three-dimensional flow from nozzles attached to reservoirs of various geometries, a generalization of the shock tube concept. Our research focuses on the behavior of the erupting material rather than, for example, on the fracture mechanics of host rock, the geochemistry of the fluids, or on magma-water interactions [Wohletz and McQueen, 1983]. In particular, a detailed study is made of the jet that expands into the external atmosphere during a laboratory-scale eruption. The shape and properties of the external flow fields of eruptions, expanding into an infinite half-space, are studied in relation to changing reservoir conditions. We examine the influence of flow unsteadiness, compressibility, and turbulent mixing. Relations between propagating flow fronts and atmospheric shock and compression waves are described. Some of the questions that we address are:

1. How does the atmosphere in the vicinity of an eruption respond to the eruption of fluids of differing thermodynamic properties?
2. What are the flow characteristics of the first fluid out of the vent, that is, of the unsteady flow before steady flow is established?

3. How does the steady flow regime evolve from the unsteady flow? At a fixed point in space, what is the relation between the conditions of unsteady and steady flow, i.e., what is the thermodynamic history at a point?

4. What influence does entrainment of ambient atmospheric air at the edges of the jet have on the flow of the fluid within the jet, and how does it depend on the properties of the two fluids?

5. What is the relation between the observable properties of the external flow and the internal history of the reservoir as the discharge develops?

\section{Volcanic Jets and Plumes}

To illustrate the evolution of volcanic jets, it is useful to consider a simplified large-scale, gas-rich eruption that produces a caldera. Figure 1 shows how an eruption sequence might be divided into four stages: (1) initial conditions (the states of the atmosphere, magma, and host rock immediately prior to an eruption); (2) triggering (the event that exposes a reservoir at high pressure to ambient pressure) and development of flow; (3) quasi-steady flow (during which constant flow conditions near the source persist for measurable times); and (4) decline (when flow velocities and mass flux are small).

Relative durations of the stages depend on circumstances of triggering, reservoir size and geometry, and fluid properties. For example, in some sequences, caldera collapse might not occur, as in small Hawaiian eruptions. On the other hand, fluid flow processes may overlap several of these stages, e.g., caldera collapse may actually begin when an eruption is triggered and continue until after the eruption terminates. Nevertheless, these four stages provide a framework for comparing laboratory experiments to volcanic events.

Jets and plumes are fluid flows in which mass, momentum, and energy are convected from an isolated source into a sur-

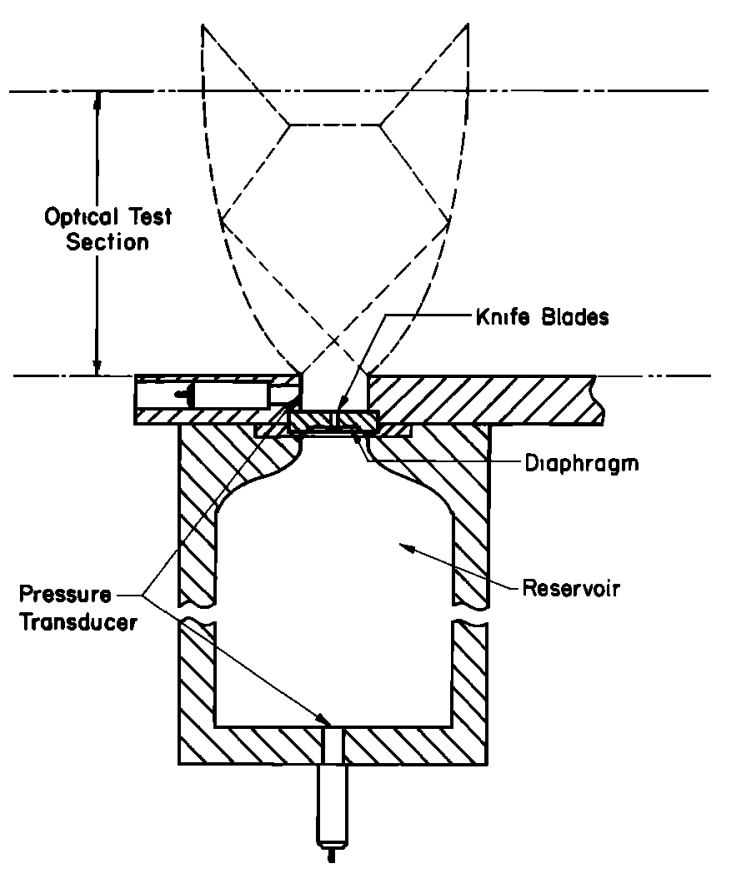

Fig. 2a. Cross section of the reservoir used for the experiments. The nozzle diameter is $1.5 \mathrm{~cm}(0.6 \mathrm{in}$.). 
rounding atmosphere. In terms of end-member behavior, pure plumes are entirely buoyancy driven, and pure jets are entirely momentum driven. As commonly described, plumes are driven primarily by buoyancy, while jets can be momentum driven or buoyancy driven [Turner, 1973; Chen and Rodi, 1980]. Thus buoyant jets may equally well be referred to as forced plumes.

It is well known that the effects of gravity are frequently important in the development of volcanic jets and plumes, but it has only recently been fully appreciated that in many volcanic flows, particularly in those described as "explosive," the momentum imparted to the fluid by the source is substantially greater than that acquired from (or lost to) gravity, so the effects of gravity may be neglected [Wilson, 1980; Kieffer, 1982a]. It is to these flows that we have directed our attention in this work. Accordingly, we refer to the flows as "jets" in order to emphasize both that the rapidly developing volcanic flows we treat are principally momentum driven and that the laboratory experiments do not model gravitational effects.

\subsection{Multiphase Flows}

Upon exit from the conduit, most volcanic jets are a dispersed multiphase mixture of liquid droplets and ash particles in vapors and gases. Considerable mass transfer takes place between the particulate and vapor phases by exsolution of dissolved gases and by evaporation and condensation of the volatile components. Analytical treatment of the flow is simplified when (1) the mass exchange is small, (2) the momentum and energy exchange between the phases occurs rapidly enough that their velocities and temperatures are nearly equal, and (3) the concentration of ash is so small that interactions (including collisions) between particles are unimportant. Under these conditions, the mixture approximates a perfect gas whose density is equal to that of the mixture and whose pressure is equal to that of the gaseous phase. The fluid properties are described by a gas constant $R$ and an isentropic exponent $\gamma$ that are not simply the gas constant and the ratio of specific heats $c_{p} / c_{\omega}$, respectively, of the gas, but are mass weighted with the corresponding values for the solid. In this case the fluid is called a pseudogas, and the well-known theory of single-phase gas dynamics can be used to describe the behavior of the jet. Typically, the sound speed of the pseudogas mixture is so low that the flow velocity is supersonic. Furthermore, the ratio of specific heats of the pseudogas is very

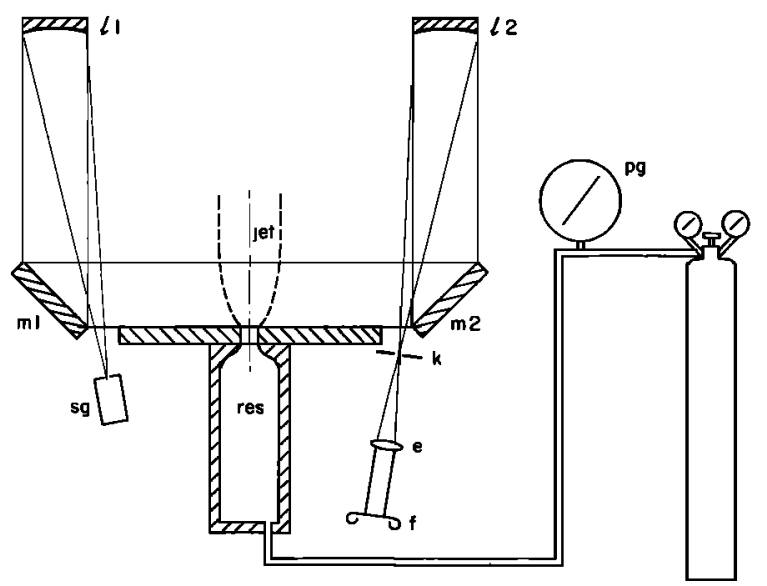

Fig. 2b. Layout of the experimental facility: sg, spark gap light source; 11 and 12 , collimating mirrors; $M 1$ and $M 2$, plane mirrors, $k$, schlieren knife edge or dot; e, camera lens, f, film plane; pg, pressure gauge and high-pressure gas supply. Not to scale.
TABLE 1. Properties of Gases Used in Experiments

\begin{tabular}{lcccccc}
\hline & $\begin{array}{c}\text { Mol. } \\
\text { Weight }\end{array}$ & $\begin{array}{c}\text { Critical } \\
\boldsymbol{T}, \\
\text { K }\end{array}$ & $\begin{array}{c}\text { Critical } \\
\boldsymbol{P}, \\
\text { MPa }\end{array}$ & $\begin{array}{c}\text { Boiling } \\
\text { Point, } \\
\text { K }\end{array}$ & $\gamma$ & $\begin{array}{c}c, \\
\mathrm{~m} / \mathrm{s}\end{array}$ \\
\hline $\begin{array}{l}\text { Helium } \\
\text { He }\end{array}$ & 4 & 5.2 & 0.228 & 4.22 & 1.67 & 1002 \\
$\begin{array}{l}\text { Nitrogen } \\
\mathbf{N}_{2}\end{array}$ & 28 & 126.2 & 3.4 & 77.4 & 1.40 & 353 \\
$\begin{array}{l}\text { Freon 12 } \\
\mathrm{CCl}_{2} \mathbf{F}_{2}\end{array}$ & 121 & 385 & 4.12 & 243.4 & 1.137 & 153 \\
$\begin{array}{l}\text { Freon 22 }_{2} \\
\mathrm{CHClF}_{2}\end{array}$ & 86.5 & 369.2 & 4.98 & 232.4 & 1.184 & 185 \\
\hline
\end{tabular}

$T$, temperature. Sound speed $c$ calculated for room temperature $27^{\circ} \mathrm{C}$.

nearly unity, so the flow is essentially isothermal. However, very little is known about the behavior of transient jets such as those that occur in explosive volcanism, even for such relatively simple materials as gases or pseudogases. Steady free jets have been well documented by laboratory studies [cf. e.g., Ricou and Spaulding, 1961], but little work has been done on the unsteady conditions that occur at the start-up of these flows. Therefore before examining laboratory jets of nonideal fluids for application to analyses of volcanic flows, it is necessary to develop a data base of the behavior of transient jets of pure gases. Even so, these preliminary studies serve to model those explosive volcanic eruptions that may be reasonably analyzed by the theory of single-phase gas dynamics. All current models of gaseous volcanic eruption dynamics assume that an erupting gas-pyroclast mixture behaves as a pure gas or pseudogas [McGetchin, 1968; McGetchin and Ulrich, 1973; Wilson, 1976, 1980; Self et al., 1979; Wilson et al., 1980; Wilson and Head, 1981; Eichelberger and Hayes, 1982; Kieffer, $1982 a, b ;$ Sparks and Wilson, 1982]. Hence these laboratory experiments are directly relevant to interpretation of volcanic behavior based on theories to date.

If spatial or temporal variations of the flow are too rapid for the velocity and temperature of liquid and solid particles to follow, then "relaxation phenomena" occur during the accelerative and heating stages, and the pseudogas approximation is inapplicable. Such a flow can only be described by a two- or three-fluid theory, no satisfactory version of which exists at this time. Additional (and usually intractable) complexity results' where interphase mass transfer occurs. If the particulate material is sufficiently concentrated that interparticle interactions occur, it is not even known what physical effects to expect! Studies of laboratory and industrial fluidized beds [see, for example, Rowe, 1971; El-Kaissey and Homsy, 1976] in which gas velocities are generally smaller than those of interest here show that even those flows are inherently unstable, so no steady uniform flow state can exist. Laboratory experiments designed to resolve some of these issues are needed.

\subsection{Nonsteady Flows}

Explosive volcanic eruptions initially generate flows that are inherently nonsteady; that is, no transformation into a coordinate system moving at constant velocity relative to the earth's surface (which we refer to as the laboratory frame) can render the flow steady. In particular, in the laboratory frame the "head" of the jet, that is, the first fluid to exit from the source and to push continuously out into the surrounding atmosphere, is inevitably time varying. However, if conditions in 


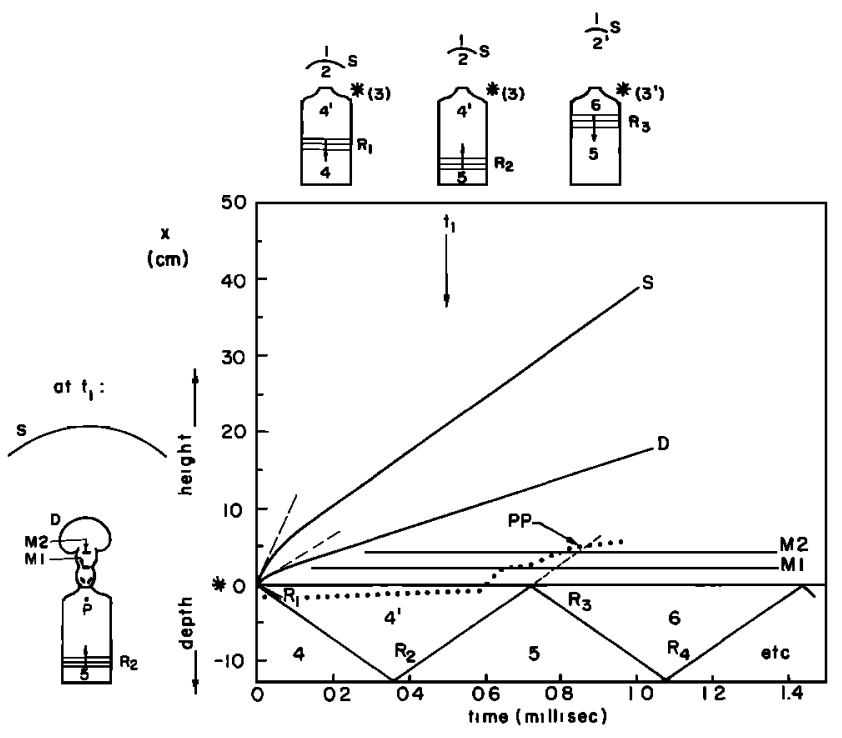

Fig. 3. An $x-t$ diagram showing wave and fluid motion in the axial direction for nitrogen jet; initial pressure 7.25 bars, 13-cm-long reservoir. Above the reservoir the flow is three dimensional, so the graph represents the on-axis behavior. $S$, atmospheric shock or compression wave; $D$, flow head; $R_{1,2.3} .$. , rarefaction waves; $M_{1.2}$, Mach disks; $P P$, path of fluid particle. The velocities of the waves shown on the graph and flow properties in the different fields are given in Table 2. The atmospheric shock $S$ is shown with a velocity initially greater than acoustic, but decaying quickly to acoustic velocity with distance because of radial spreading. The flow head $D$ is shown leaving the orifice at sonic velocity but with velocity decreasing rapidly to the measured value of $250 \mathrm{~m} / \mathrm{s}$. Note the accelerations and decelerations of the particle $P P$ as it passes consecutively through the first rarefaction wave, the area change, the rarefaction waves in the jet (not shown) and the Mach disks.

the reservoir remain relatively constant for times longer than several acoustic transmission times across the jet, the jet flow near the source is quasi-steady; the flow only becomes completely steady when reservoir conditions are truly constant and the jet head has propagated far downstream. In the steady or quasi-steady portion of a supersonic jet, acoustic waves and shock waves may occur, but they do not move relative to the lab frame.

During an eruption, conditions within the reservoir change with time (e.g., because of the finite size of the reservoir, because the magma properties change, or because the boundary conditions may change). The changes are communicated to the external flow field by waves that propagate from the reservoir through the jet fluid; these waves move downstream at the local speed of sound relative to the jet fluid. The smallest time for significant changes in the reservoir is the acoustic transit time over the largest dimension of the source chamber, but if a substantial constriction ("throat") occurs at the exit, the decay time can be much longer; many acoustic transit times may be required belore reservoir conditions substantially change. Quasi-steady flow occurs in many volcanic eruptions where a narrow conduit or vent overlies a large reservoir. Probable exceptions are in brief eruptions such as Vulcanian or Strombolian bursts. One purpose of the present study is to determine the dependence of quasi-steady flow on initial conditions and reservoir geometry.

\subsection{Compressibility}

In subsonic flow, changes of fluid density due to acceleration and deceleration of the flow are very small, and the flow is termed "incompressible." Conservation of energy or, more directly, momentum is expressed by the Bernoulli equation, which for the low-speed steady flow of an inviscid non-heatconducting fluid is

$$
P_{0}=P+\frac{1}{2} \rho u^{2} \quad P_{0}, \rho=\text { const }
$$

where $\boldsymbol{P}_{0}$ is the stagnation pressure, $P$ is the static pressure, $u$ is the flow velocity, and $\rho$ is the density. The pressure $P$ responds solely to changes of velocity and is not a thermodynamic variable. On the other hand, as the Mach number $M$ ( $=u / c$, where $c$ is sound speed) increases, the effects of compressibility become more important, and Bernoulli's equation in the above form does not apply but instead becomes

$$
\frac{P_{0}}{P}=\left(1+\frac{\gamma-1}{2} M^{2}\right)^{\gamma /(\gamma-1)}
$$

Now the pressure plays both a dynamic and a thermodynamic role. For supersonic velocities $(M>1)$, the nature of the density variations changes, and for example, the density (and pressure) can undergo large discontinuous changes in shock waves. (For a discussion of compressible flow, see Thompson [1972].) The most important property of supersonic free jets for volcanic applications is that the pressure and density can vary by large factors along the axis of the jet, while in subsonic jets the pressure is nearly atmospheric throughout and the density is constant. An initially subsonic jet can change density in response to decreasing ambient pressure, say, with in-
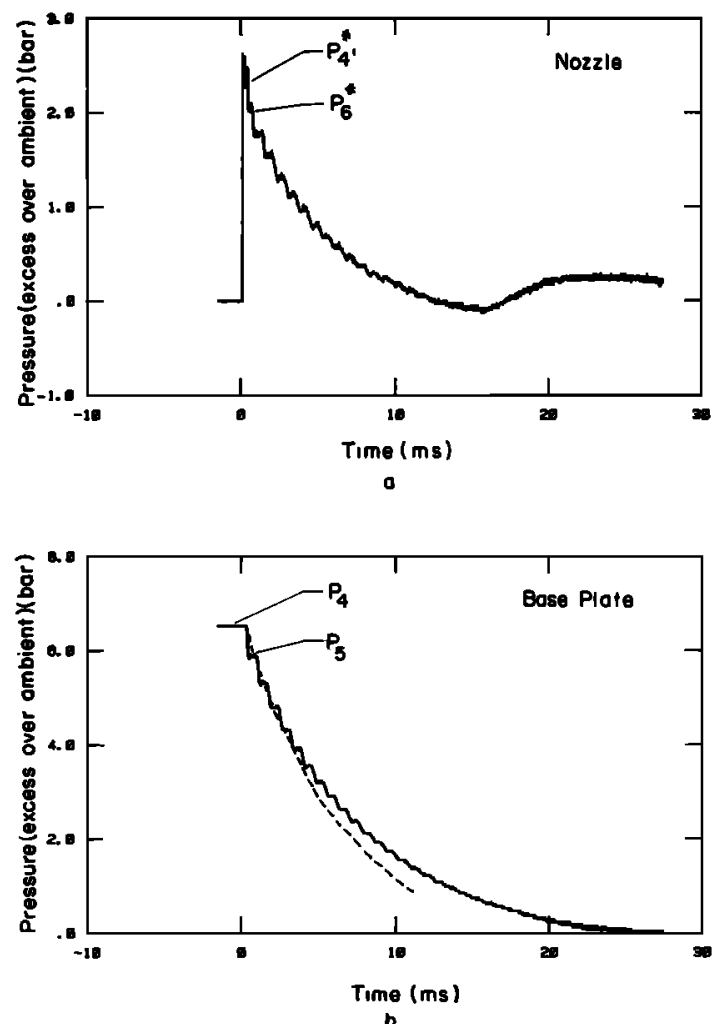

Fig. 4. (a) Pressure history recorded by the pressure transducer located in the nozzle just outside of the diaphragm for nitrogen emptying from a reservoir $13 \mathrm{~cm}$ long, initially at 7.25 bars. $P_{4},{ }^{*}, P_{8}{ }^{*}$ indicate quasi-steady conditions in the nozzle exit. (b) Same for the transducer located at the bottom of the reservoir. $P_{4}$ and $P_{5}$ indicate initial and quasi-steady conditions, respectively. Dashed line shows result from pressure decay model (10). 


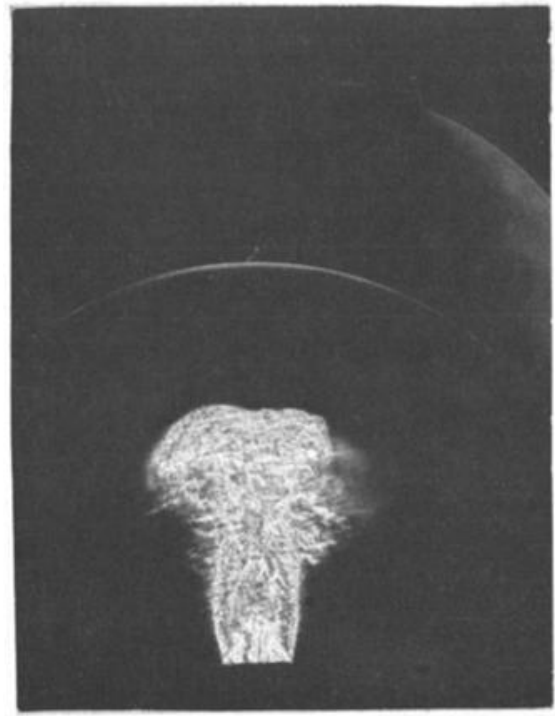

a

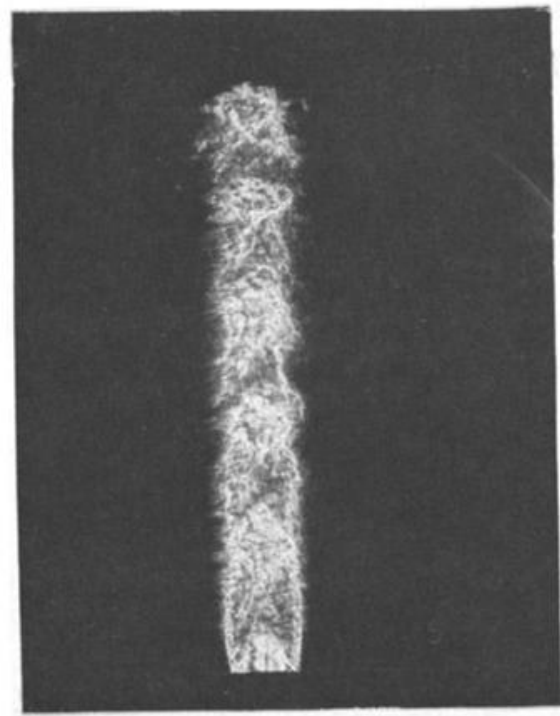

C

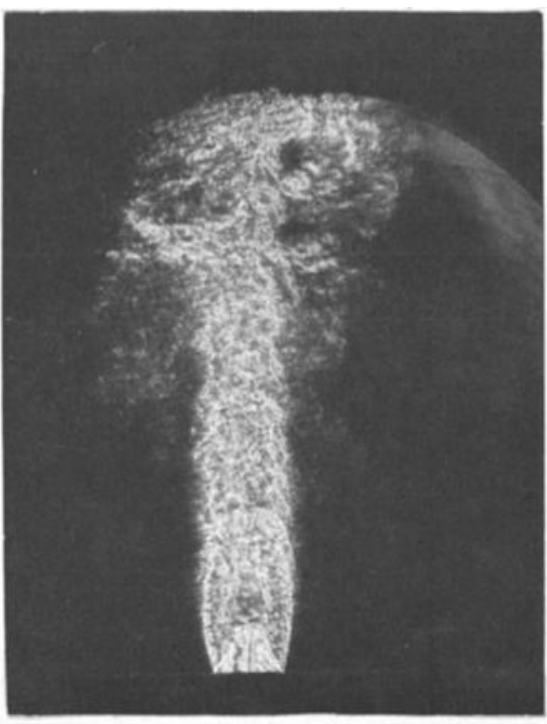

b

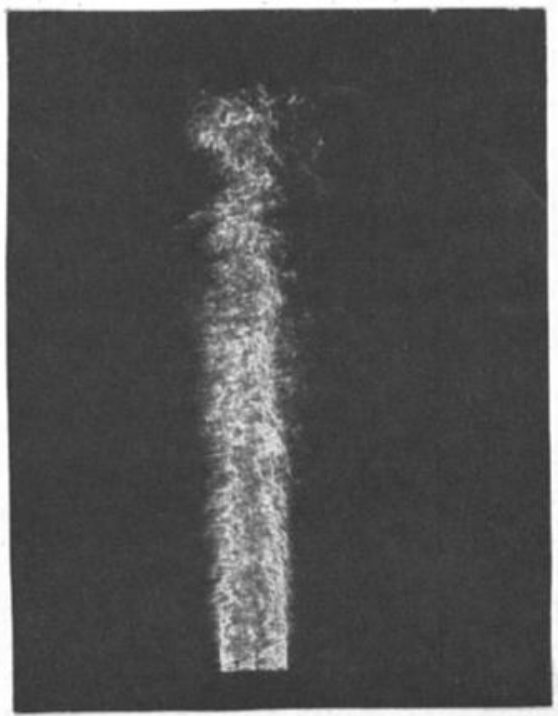

d

Fig. 5. Schlieren photos of a nitrogen jet development; initial pressure 7.25 bars, reservoir length $13 \mathrm{~cm}$, jet exit diameter $1.5 \mathrm{~cm}$. (a) $292 \mu \mathrm{s}$, reservoir at state $\left(4^{2}\right), P_{4}=6.9$ bars. Note the atmospheric shock, the vortexlike flow head, and the faint waves converging toward the axis and a short Mach disk just below the flow head. (b) At $702 \mu$ s, reservoir still at state $\left(4^{\prime}\right)$. Note the similarity of the near-field structure to that in Figure $5 a$, the multiple rarefaction and shock sequences, and the enlargement of the fin diameter than in Figure $5 b$. (d) At $9.92 \mathrm{~ms}$, reservoir pressure is 2.6 bars. Subsonic jet. Note the orifice and are smaller in deactions. An estimate of experimental reproducibility can be obtained by comparing Figure $5 c$ to Figures $6 c$ and $6 d$. All were taken at the same nominal times in different runs. Note also that Figures $9 c$ and $9 d$ and Figure $7 b$ can be fitted into the sequence here, so that photos of seven different stages of the eruption of nitrogen from a reservoir initially at 7.25 bars are shown in this paper.

creasing altitude in the ambient atmosphere, only by becoming "compressible," e.g., supersonic. Another mechanism for changing the density of jet fluid, namely, mixing and entrainment (see section 2.4), does not depend to first order on external pressure gradients.

Velocities can be high subsonic or even supersonic in geologic flows, particularly in geothermal and volcanic settings [Wilson et al., 1980; Kieffer, 1982b]. Velocities in these set- tings are commonly $100-500 \mathrm{~m} \mathrm{~s}^{-1}$ on earth and, for example, more than $1 \mathrm{~km} \mathrm{~s}^{-1}$ on Io. Compressibility becomes important in these flows, not generally because of abnormally high velocities, but because the sound speed of the flowing material can be low. For example,

1. The sound speed of boiling water is in the range of a few tens to $100 \mathrm{~m} \mathrm{~s}^{-1}$ over a large range of steam quality, but can be as low as $1 \mathrm{~m} \mathrm{~s}^{-1}$ [cf. Kieffer, 1977]. Therefore flows in 


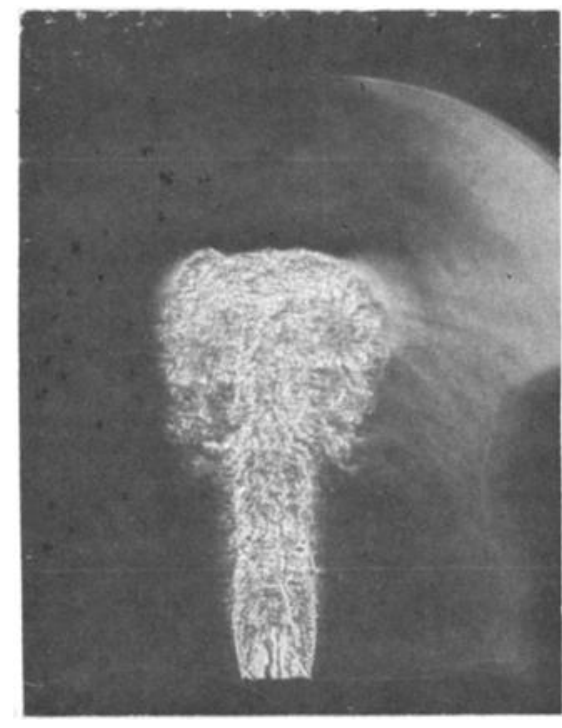

a

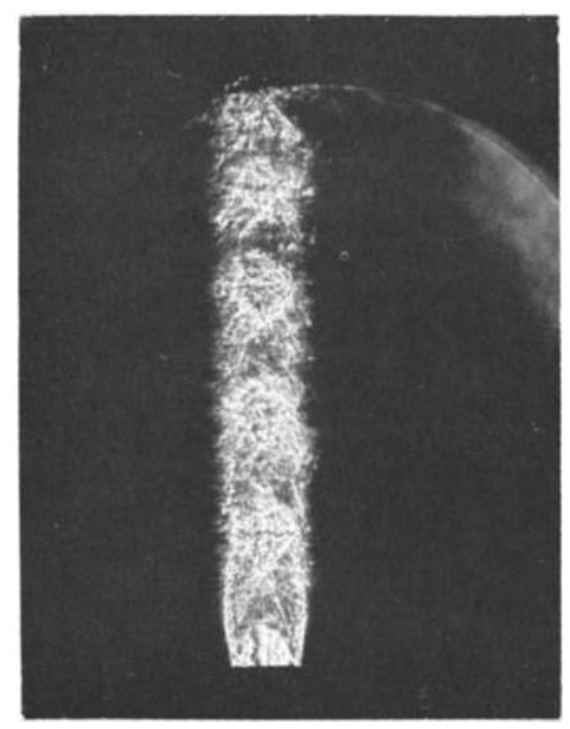

C

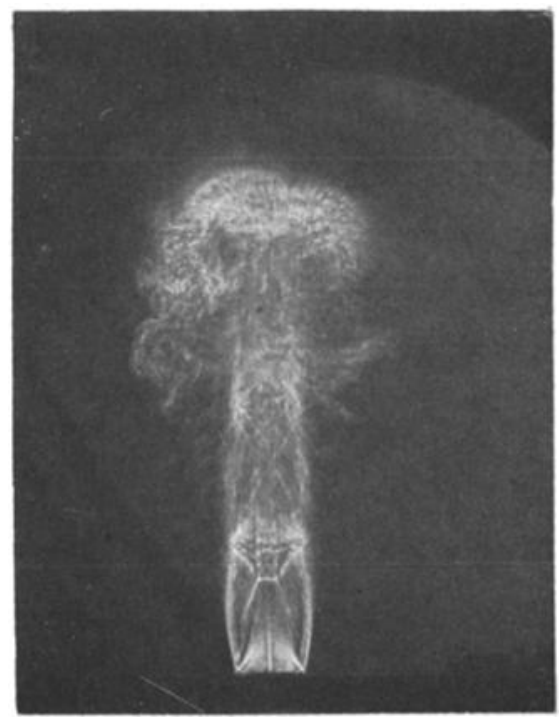

b

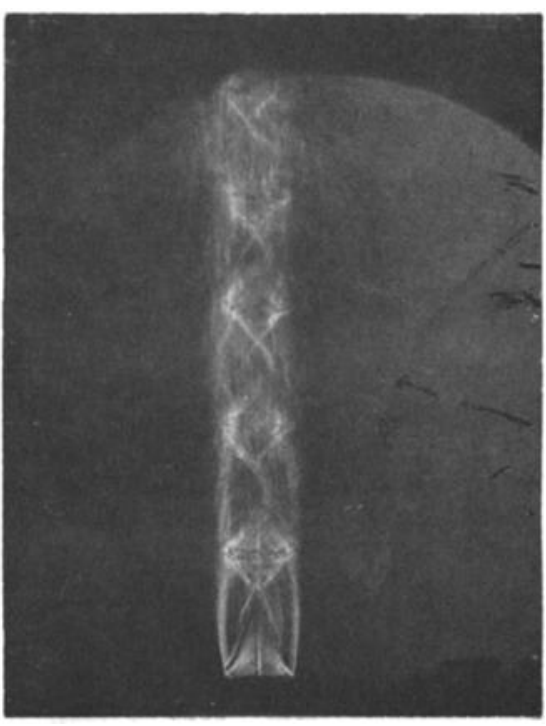

d

Fig. 6. Schlieren photographs comparing images obtained with two different spark durations: $1 \mu \mathrm{s}$ (left) and $10 \mu \mathrm{s}$ (right). All photographs are of nitrogen erupting from a 13-cm-long reservoir initially at 7.25 bars; jet exit diameter $1.5 \mathrm{~cm}$. $(a$ and $b$ ) taken $500 \mu \mathrm{s}$ after diaphragm rupture when the reservoir was at state (4'). ( $c$ and $d$ ) Taken at $2.25 \mathrm{msec}$ when the reservoir pressure was about 5.75 bars. The illumination of Figures $6 b$ and $6 d$ provides the best visualization of the rarefaction waves that emanate from the orifice, the intercepting shocks that form when the rarefactions reflect from the flow boundary, the Mach disk shock that stands across the flow on the axis, and the oblique shock waves that emanate from the Mach disk. (The small bright line extending out from the orifice in the center of the flow field is the wake of the knife blades.)

geyser or volcanic eruptions, or in producing geothermal wells, involving the flow of boiling water at speeds from a few meters to a few tens of meters per second can have high subsonic or even supersonic Mach numbers.

2. Wet steam can have a sound speed of only a few to 100 $\mathrm{m} \mathrm{s}^{-1}$. Many volcanic and geothermal jets consist principally of wet steam and can have fluid velocities as large as the sound speed.

3. Gas flows containing a large mass of entrained particulate material can have very low sound speeds, perhaps as low as $50 \mathrm{~m} \mathrm{~s}^{-1}$ [Marble, 1963, 1970; Rudinger, 1965]. Therefore particulate-laden flows from volcanoes can be supersonic.

In most of these cases, the flow velocities are subsonic relative to the surrounding atmosphere, e.g., much less than the sound speed in air $\left(330 \mathrm{~m} \mathrm{~s}^{-1}\right)$. It is not known what effect, if any, such a disparity between external and internal Mach numbers can have on the behavior of the flow.

A volcanic jet can be supersonic when the reservoir pressure is more than about twice the atmospheric pressure, as is frequently the case. When the constriction at the exit is modest 
or severe (e.g., when a volcanic vent or conduit is small compared with the feeding reservoir), the jet is "underexpanded" because the exit pressure, though less than in the reservoir, is much greater than atmospheric. Typically, underexpanded jets grow rapidly in diameter as they expand into the atmosphere.

\subsection{Density Effects}

Fluid densities in volcanic jets vary over several orders of magnitude; pure steam jets can be less dense than the surrounding air, whereas particulate-laden jets are much denser than the atmosphere. The high density introduces important gravitational effects and affects the flow dynamics. Even though steady subsonic and supersonic jets have been studied extensively in the laboratory, there is little information available about the effects of greatly disparate jet and atmospheric densities. Dense subsonic jets flowing into a less dense medium (such as a water jet into air) grow downstream much less rapidly than jets of density similar to the surrounding atmosphere (such as an air jet into air) [Tombach, 1969], but the mechanism for this is not clear. Presumably, the inertia of the jet makes it less susceptible to the development of contortions on its surface by instability. Distortion of jet boundaries is the process by which entrainment, turbulent mixing, and therefore jet growth occur. The principal instabilities in dense jets are the Kelvin-Helmholtz instability of shearing flow and the Rayleigh-Taylor instability of an accelerating nonuniform fluid.

As mentioned above, the diameter of underexpanded supersonic jets tends to grow rapidly in the immediate vicinity of the orifice. Since a dense pseudogas has a smaller ratio of specific heats $\gamma$ than a less-dense one does, its initial growth tends to be greater, because the angle by which the flow is deflected (the Prandtl-Meyer angle) in the expansion wave that reduces the exit pressure to ambient, increases with decreasing $\gamma$. Thus the mechanisms by which jet diameter increases downstream are different for subsonic and supersonic jets, and the effect on each of increasing the density of the jet fluid is opposite.

\subsection{Scaling}

Our experiments are at reduced scale, with different fluids, and at lower temperature and pressure than in volcanic eruptions. In order to simulate volcanic eruptions, it is necessary to scale geometric, dynamic, and thermodynamic quantities.

2.5.1. Geometric. Spatial and temporal scales of a flow process are interrelated; their ratio is the characteristic flow velocity. The best choice of such a velocity in a sonic or supersonic jet is the sound speed of the jet fluid. Because of the universality of the behavior of multiphase fluids, the velocities in the experimental jets are of the same order as in volcanic jets (tens to hundreds of meters per second). Because the spatial dimensions of the experimental apparatus are at least 5 orders of magnitude smaller than volcanoes, the laboratory time scales are about $10^{-5}$ times those of volcanic eruptions. That is, $1 \mathrm{~s}$ in the life of a volcanic jet corresponds to about 10 $\mu \mathrm{s}$ in the life of a laboratory jet.

2.5.2. Dynamic. The important dynamic quantities are the various forces that can alter the momentum (and energy) of the fluid. The validity of the simulation can be judged by comparing the numerical values of nondimensional parameters that express the ratios of forces. In momentum-driven flows the inertia of the fluid is the reference force. Other important forces to consider are viscous and gravitational, so the relevant nondimensional parameters are the Reynolds and
TABLE 2. Summary of Initial States and Calculated Early Flow Conditions for Experiments

\begin{tabular}{|c|c|c|c|c|}
\hline & $\mathrm{He}$ & $\mathbf{N}_{2}$ & Fr 22 & Fr 12 \\
\hline$P_{4}$, bar & 7.25 & 7.25 & 7.25 & 7.25 \\
\hline$c_{4}, \mathrm{~m} / \mathrm{s}$ & 1002 & 353 & 185 & 153 \\
\hline$\rho_{4}, \mathrm{~kg} / \mathrm{m}^{3}$ & 1.13 & 7.96 & 25.4 & 35.8 \\
\hline$T_{4}, \mathrm{~K}$ & 300 & 300 & 300 & 300 \\
\hline$P_{4}$, bar & 6.85 & 6.92 & 6.97 & 6.96 \\
\hline$c_{4}, \mathrm{~m} / \mathrm{s}$ & 990.9 & 350.6 & 184.4 & 152.6 \\
\hline$\rho_{4}, \mathrm{~kg} / \mathrm{m}^{3}$ & 1.09 & 7.70 & 24.5 & 34.6 \\
\hline$T_{4}, \mathrm{~K}$ & 298.3 & 299.0 & 299.5 & 299.5 \\
\hline$v_{4}, \mathrm{deg}$ & 20.3 & 25 & 34.6 & 33 \\
\hline$P_{4} *$, bar & 3.55 & 3.84 & 4.13 & 4.20 \\
\hline$c_{4^{*}}^{*}, \mathrm{~m} / \mathrm{s}$ & 868 & 32.2 & 177 & 150 \\
\hline$\rho_{4}{ }^{*}, \mathrm{~kg} / \mathrm{m}^{3}$ & 0.73 & 5.01 & 21.5 & 22.2 \\
\hline$T_{4}^{*}, \mathrm{~K}$ & 225 & 250 & 274 & 281 \\
\hline$m_{4}^{*}, \mathrm{~kg} \mathrm{~m}^{-2} \mathrm{~s}^{-1}$ & 300 & 1240 & 730 & 630 \\
\hline$P_{5}$, bar & 6.53 & 6.60 & 6.68 & 6.69 \\
\hline$P_{6}$, bar & 6.13 & 6.30 & 6.41 & 6.43 \\
\hline
\end{tabular}

For notation see text and appendix. The initial pressure $P_{4}$ is estimated to be $7.25 \pm 0.3$ bars; the initial temperature $T_{4}$ is taken to be room temperature, $27 \pm 1{ }^{\circ} \mathrm{C}$. The initial densities $\rho_{4}$, were obtained from tables of thermodynamic properties; $c_{4}$ was calculated from $c_{4}=(\gamma R T)^{1 / 2}$.

Froude numbers, respectively. Because the experiments do not simulate gravity, we discuss only viscous effects. The Reynolds number is

$$
\operatorname{Re}=\frac{\rho U L}{\mu}
$$

where $L$ is a characteristic length, usually the diameter of the jet, $U$ is a similar characteristic velocity, $\rho$ is the fluid density, and $\mu$ is the viscosity of the gaseous component of the jet.

In gassy volcanic eruptions, viscous forces play essentially no role. That is, the Reynolds number is very large. For example, for many volcanic jets $L \sim 1 \mathrm{~km}, U \sim 100 \mathrm{~m} \mathrm{~s}^{-1}, \rho \sim 20$ $\mathrm{kg} \mathrm{m}^{-3}$, and $\mu \sim 10^{-5} \mathrm{~kg} \mathrm{~m}^{-1} \mathrm{~s}^{-1}$. The corresponding Reynolds number is greater than $10^{11}$. On the other hand, typical Reynolds numbers for the experiments reported in this work are about $5 \times 10^{4}$.

Because of fluid-dynamic instability, large Reynolds number flows are turbulent. Experiments [e.g., Reynolds, 1962] show that free jets are fully turbulent for Reynolds numbers greater than a few hundred. Turbulent mixing and therefore the development of a turbulent jet is independent of viscosity. Thus in both the lab experiments and in volcanic jets, fluid viscosity has no effect on the structure of the jet. The only issues concerning Reynolds number modeling in the present study are

1. The turbulence level of the reservoir fluid as it enters the jet should approximate that of the full-scale flow, which can be achieved by proper experimental design.

2. The jet Reynolds number should be large enough that a range of turbulent eddy sizes occurs in the flow sufficient to approximate the turbulence dynamics [Townsend, 1976] of actual volcanic jets. For the Reynolds numbers of these experiments the ratio of maximum to minimum eddy sizes is of order 100. The maximum eddy size is of the order of the jet diameter, and the minimum eddy size is the Kolmogorov microscale, at which viscous dissipation occurs [Tennekes and Lumely, 1972].

2.5.3. Thermodynamic. If during laboratory experiments the thermodynamic trajectory of the model fluid, from initial conditions to downstream infinity, approximates that of the 


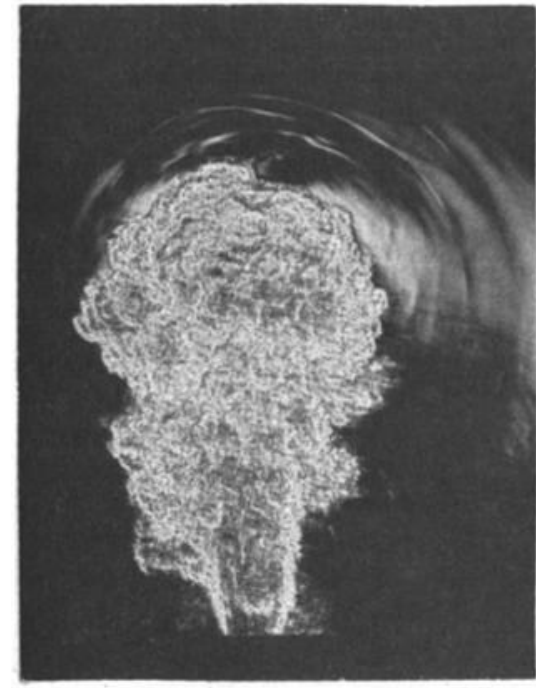

a

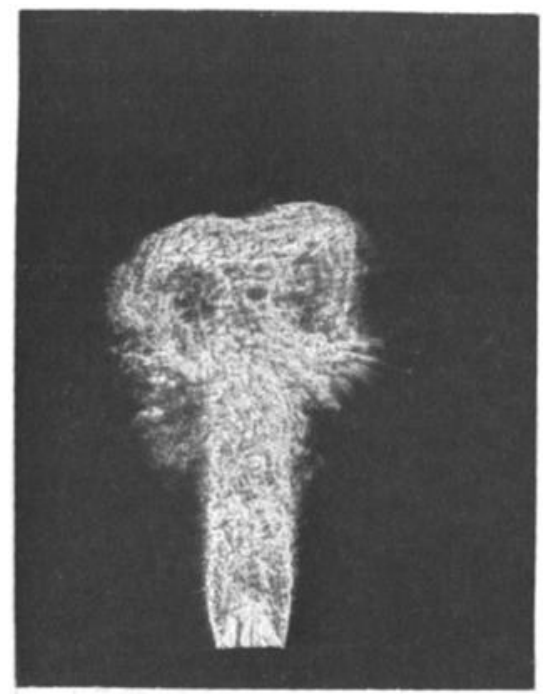

b

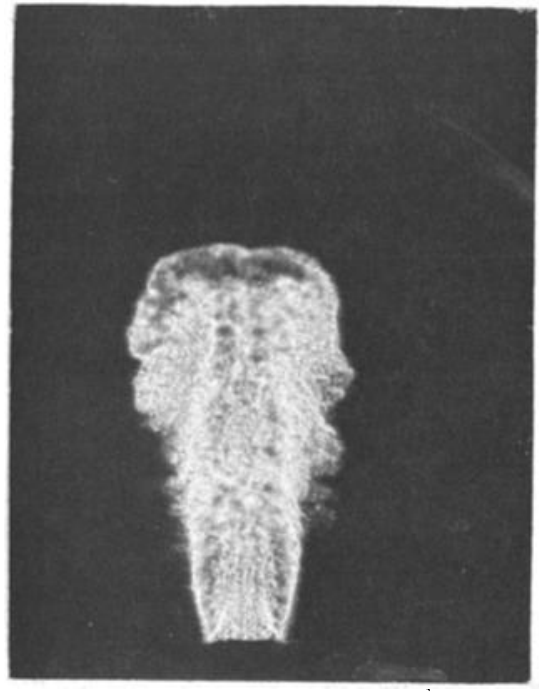

C

Fig. 7. The structure of the flow heads on jets of similar size: (a) helium jet at $410 \mu \mathrm{s},(b)$ nitrogen jet at $516 \mu \mathrm{s}$, and (c) Freon 22 jet at $620 \mu \mathrm{s}$. All eruptions are from reservoirs initially at 7.25 bars; jet exit diameter $1.5 \mathrm{~cm}$. Note the relatively large head on the helium jet and the well-formed ring vortex structures on the nitrogen and Freon jets. The times at which these photos were taken provide an indication of the different velocities of the jets.

gases in an actual volcanic jet, it can be said that the simulation is accurate. This principle is expressed formally by the Law of Corresponding States [Hirschfelder et al., 1954], a similarity law which states that if thermodynamic variables are properly normalized by their values at the critical point, all pure substances behave similarly. In particular, when normalized properly, the temperature-entropy diagrams are the same (see section 5.1). Consequently, insofar as the Law of Corresponding States applies, it is possible to model the fluiddynamic and thermodynamic behavior of one fluid by another, more convenient, one. The test fluids used in the present experiments are chosen to simulate the condensible vapors and pseudogases of volcanic jets as closely as possible.

\section{The EXPERIMENTS}

\subsection{Apparatus}

The experimental apparatus is shown schematically in Figure 2. The test fluid is pressurized in a reservoir that is sealed from the atmosphere by a thin aluminum diaphragm (Figure $2 a$ ). The diaphragm ruptures at a prescribed value of the reservoir pressure, allowing the fluid to expand into the atmosphere. Use of cruciform knife blades fixed just downstream of the diaphragm insures that diaphragm rupture reliably occurs within less than $0.01 \mathrm{MPa}$ of the design value and that the rupture geometry is repeatable. Diaphragm rupture takes about $1 \mathrm{~ms}$, but the instant of rupture is not controlled in the present experiments.

The reservoirs are designed as convergent nozzles to ensure sonic flow at the throat and supersonic flow in the external flow. Thus the experimental configuration resembles a volcanic system in which a magma reservoir is tapped by a straight-walled or upward converging fissure, not one in which the fissure feeds a diverging surface crater. If such a geometry were incorporated into the laboratory apparatus, many flow features near the throat in the region of supersonic flow would occur below the field of view of the optical system.

Pressure histories in the reservoir are measured with pi- ezoelectric transducers at two different locations and are recorded on a digital oscilloscope. One pressure transducer at the bottom of the reservoir records the high initial and subsequently decreasing pressure. The other transducer, at the top of the apparatus just outside the diaphragm, initially records atmospheric pressure, then follows a sudden increase to the exit pressure and finally a subsequent decrease, paralleling the decline of the interior reservoir pressure. To date, the maximum ratio of initial reservoir pressure to ambient atmospheric pressure tested has been $7: 1$.

The development of the external flow field is recorded by high-speed shadow and schlieren photography (Figure $2 b$; cf. Liepmann and Roshko [1957]). The light source is a spark gap, triggered at a preset time after the flow begins. Data are acquired by a single Polaroid photograph for each run, and a photographic sequence of the flow evolution is obtained by repeated runs of different time delay. This method allows adequate spatial resolution (the equivalent of 30 line pairs per millimeter on a 16-mm image), which is not possible with high-speed motion picture photography. The information recorded on a photograph depends on the duration of the spark gap. A short spark duration (1 $\mu$ s) highlights the small-scale turbulence in the shear layers at the edge of the jet; however, it obscures the internal jet structure. Longer sparks ( $\gtrsim 10 \mu \mathrm{s})$ average out the unsteady motions of fine-scale turbulence, thereby providing more resolution of steady internal features. Due to their motion, fluid entities such as the head are also slightly smeared out by the longer spark duration.

\subsection{Test Fluids}

The test gases studied to date include helium (He), nitrogen $\left(\mathrm{N}_{2}\right.$ ), Freon 12 (dichlorodifluoromethane, $\mathrm{CCl}_{2} \mathrm{~F}_{2}$ ), and Freon 22 (chlorodifluoromethane, $\mathrm{CHClF}_{2}$ ). Their physical and thermodynamic properties are compiled in Table 1. Helium and nitrogen are used as typical light, high sound speed vapors to provide a basis for comparison with the heavy, low sound speed vapors and multiphase fluids to be used as analogs to magmatic flows. Freon vapor has a relatively low ratio of 


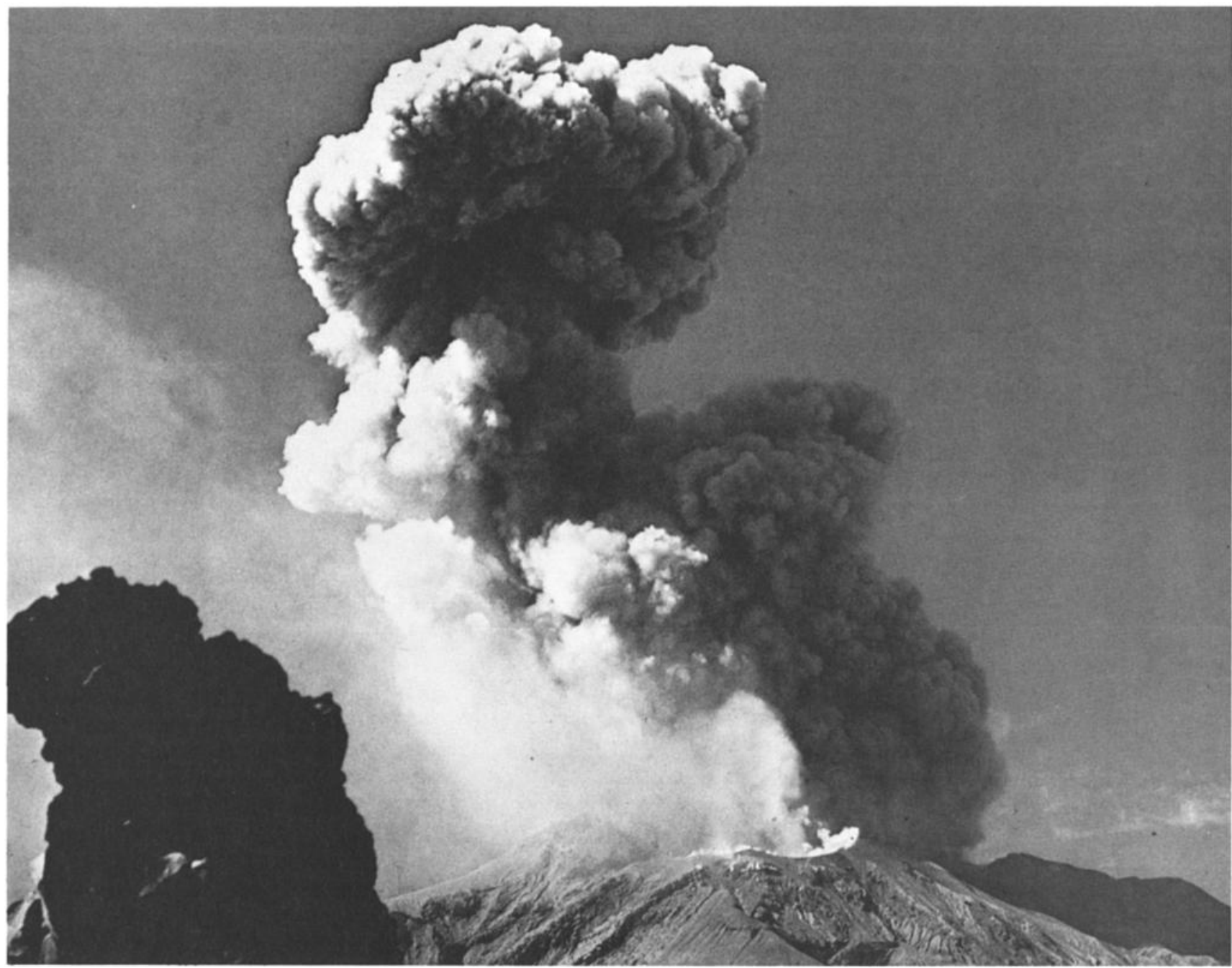

Fig. 8. A vortexlike structure at the head of a small eruption of Sakurajima, Japan.

specific heats (e.g., $\gamma=1.14$ ), like the volcanic pseudogas proposed by Kieffer [1982a] as the eruptive fluid in the lateral blast of May 18, 1980, at Mount Saint Helens $(\gamma=1.04)$; however, its density is a factor of $\mathbf{4 0}$ less than that assumed for the volcanic pseudogas. At somewhat higher pressure, the Freons can be liquified in the laboratory and provide a good analog for the two-phase flow of water because, in addition to their high density and low ratios of specific heats, near room temperature they are superheated above their boiling points by about the same amount, relative to their critical temperature, as is water at conditions thought to be representative of many shallow crustal environments, i.e., low-pressure $(P<10$ kbar $)$, low-temperature $(T<1200 \mathrm{~K})$ source regions.

\subsection{Flow History}

The evolution of jets erupting from the laboratory reservoirs can be described with reference to a space-time (or " $x-t$ ") diagram. A quantitative example taken from a typical experiment in the present study is shown in Figure 3.

When the diaphragm ruptures, an atmospheric compression or shock wave $(S)$ travels from the diaphragm into the laboratory. Simultaneously, a rarefaction wave $R_{1}$ propagates downward, signaling the diaphragm rupture to the fluid in the reservoir and accelerating and expanding it in the upward direction. The head of the rarefaction moves downward with the speed of sound of the undisturbed reservoir fluid (Table 1). The velocity of the tail of the wave through fluid that has been accelerated upward and has been cooled is smaller than the velocity of the head. However, in the experiments to date the rarefaction is rather weak, because the major acceleration occurs later when the fluid encounters the substantial area contraction $(17.4: 1)$ at the exit. Therefore the difference in velocity between the head and tail of the wave is too small to be resolved in Figure 3. A typical particle path of fluid initially in the reservoir is indicated by the dotted path $P P$. The mild acceleration by the rarefaction (to only $10 \mathrm{~m} \mathrm{~s}^{-1}$ in the case illustrated) and the strong acceleration in the contraction (to sonic velocity, $322 \mathrm{~m} \mathrm{~s}^{-1}$ ) are indicated by the greatly differing slopes of particle path in those regions.

When the rarefaction wave reaches the bottom of the reservoir, it reflects from the rigid wall as another rarefaction, $\boldsymbol{R}_{\mathbf{2}}$, and traverses again the full length of the tube. At any position $x$ in the reservoir there is an interval between passage of the first and second waves when all quantites are constant (state $\left.4^{\prime}\right)$. During this and subsequent similar intervals $(5,6$, etc.) the measured pressure histories (Figure 4) show plateaus between the passage of rarefactions. The values of pressure on successive plateaus have been designated $P_{4}, P_{5}$, etc., corresponding to the relevant flow state. It is through this series of rarefactions that the pressure drops, stepwise, to ambient. 


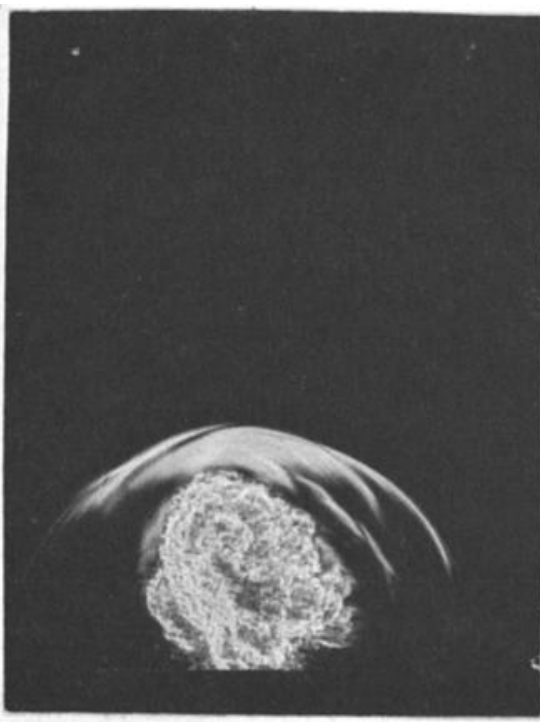

a

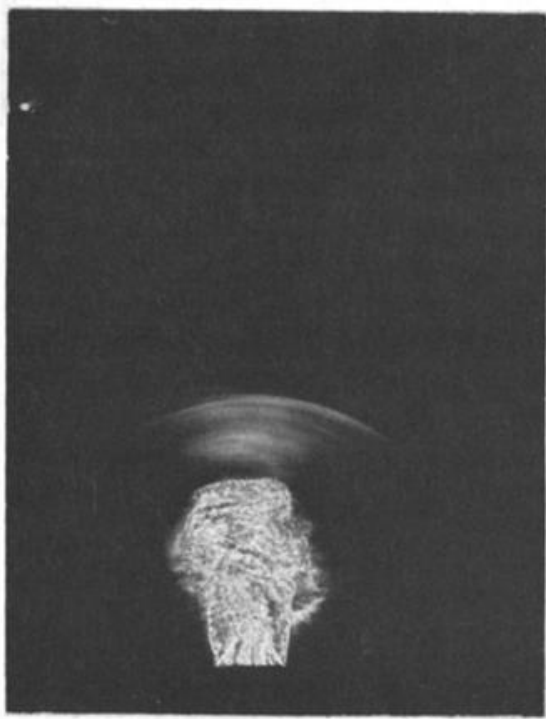

C
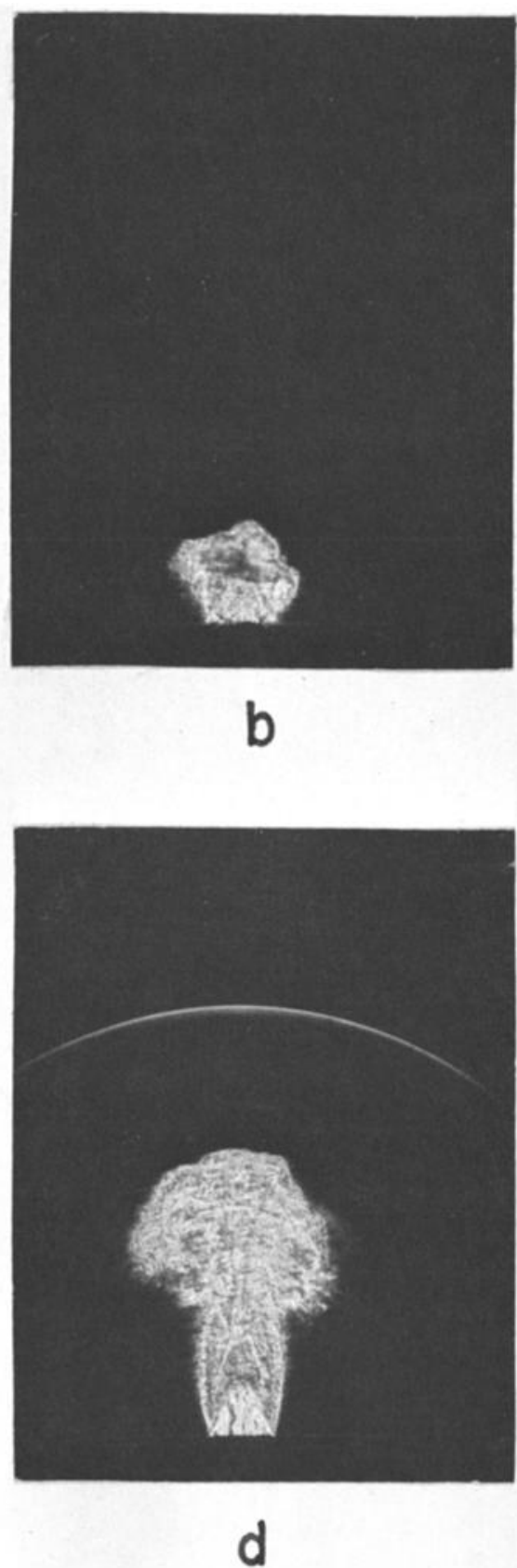

Fig. 9. Atmospheric wave fronts caused by the emergence of $(a)$ helium $(160 \mu \mathrm{s})$, (b) Freon $22(340 \mu \mathrm{s})$, (c) nitrogen (216 $\mu \mathrm{s})$, and $(d)$ nitrogen $(322 \mu \mathrm{s})$. All flows are from reservoirs initially at 7.25 bars; jet exit diameter $1.5 \mathrm{~cm}$. Note the strong shock associated with the helium eruption (Figure 9a), the lack of optically detectable atmospheric wave with Freon (Figure $9 b$ ), and the steepening of an initially dispersed wave as the nitrogen flow evolves (from Figure $9 c$ to $9 d$ ).

Thus the unsteady flow process of emptying the reservoir of its high-pressure gas occurs by a sequence of steady flow conditions at the exit. Equations for flow conditions in regions 4', 5 , and 6 are given in the appendix.

In summary, interpretation of the development of jets emanating from reservoirs of finite volume is meaningful only in reference to changing conditions in the reservoir. Extrapolation to larger, more complicated volcanic systems may be accomplished through the scaling of experimentally measured histories.

\section{Results}

Dark-background schlieren photographs (Figure 5) show the development of a nitrogen jet flowing into air from a reservoir large enough to produce quasi-steady flow near the nozzle exit. Figure 6 illustrates how the duration of the illumination enhances different flow features. The features depicted in Figures 5 and 6 are typical of the jets generated in all experiments to date. In this section we discuss the development of the flow with reference to the four stages defined in Figure 1.

\subsection{Initial Conditions}

The results presented here were obtained in runs at an initial reservoir pressure of 7.25 bars and temperature of $27^{\circ} \mathrm{C}$. A summary of conditions in the reservoir during the first few pressure plateaus, calculated from the initial conditions (state 4) and the reservoir geometry, is given in Table 2. Note partic- 
ularly that the initial densities of the gases vary by a factor of 35.

\subsection{Development of the Flow}

4.2.1. Unsteady flow at the head of the jet. The initial, rapid acceleration of fluid from the reservoir generates a starting vortex structure, which sometimes has the appearance of a vortex ring. This structure becomes the head of the jet (Figures $6 a$ and 7). Similar vortical structures commonly develop in volcanic eruptions (Figure 8) and buoyant plumes. From flow visualization studies in water it is known that the appearance of the heads of jets can vary greatly [Zukoski, 1982], but the causes for the variations have not yet been isolated and documented. Varying the density of the jet fluid has a visible effect (Figure 7); interaction of a light jet with a heavy fluid (i.e., a helium jet moving into air) yields a much more voluminous head than the inverse. The interaction has a similarly pronounced effect on the velocity of the head (approximate velocities are obtained by comparing photographs taken at different stages of flow): a few orifice diameters downstream of the exit, the helium head has slowed to one-third $(300 \mathrm{~m}$ $\mathrm{s}^{-1}$ ) of the helium exit velocity $\left(868 \mathrm{~m} \mathrm{~s}^{-1}\right)$; the nitrogen head has slowed to three-quarters $\left(250 \mathrm{~m} \mathrm{~s}^{-1}\right)$ of the corresponding exit velocity ( $322 \mathrm{~m} \mathrm{~s}^{-1}$ ); but to within experimental accuracy, the Freon heads move at exit velocity (about $175 \mathrm{~m} \mathrm{~s}^{-1}$ ). This trend may reflect the fact that entrainment of a heavy fluid has a much greater effect on the momentum of a light fluid than vice versa.

4.2.2. Atmospheric shock wave. Figure 9 shows the head of the jet and the atmospheric disturbance shortly after diaphragm rupture for three different test gases. The strength of the atmospheric wave depends on the velocity of the head, which in turn, scales with the exit velocity of the jet or, for supersonic jets, with the jet fluid sound speed. If the velocity of the head is large enough, a discontinuous (shock) wave may form in the atmosphere when the compression caused by the jet steepens by fluid-dynamic nonlinearity. Helium, with its sound speed of $1002 \mathrm{~m} \mathrm{~s}^{-1}$, produces a strong atmospheric shock near the orifice (Figure 9a). The Freons, with sound speeds of 150 and $185 \mathrm{~m} \mathrm{~s}^{-1}$, do not produce an optically detectable compression wave (Figure $9 b$ ). Nitrogen, with a sound speed of $353 \mathrm{~m} \mathrm{~s}^{-1}$, initially produces only a strong compression wave. It steepens into a shock as it travels through the atmosphere (Figures $9 c$ and $9 d$ ).

Due to the subsequent deceleration of the flow head and also to the radial spreading of the wave front, the pressure decreases rapidly behind the initial compression. As was already known at the time of the explosion of Krakatoa [Stra-

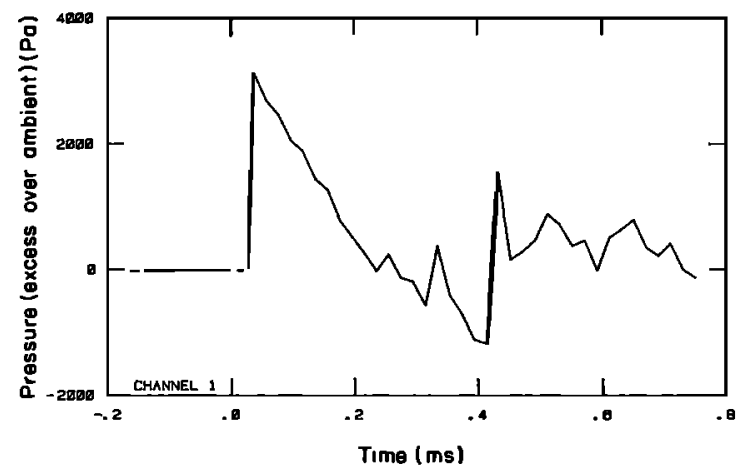

Fig. 10a. Pressure trace of the $\mathrm{N}$ wave in air measured by a microphone located 38 nozzle diameters from the orifice.

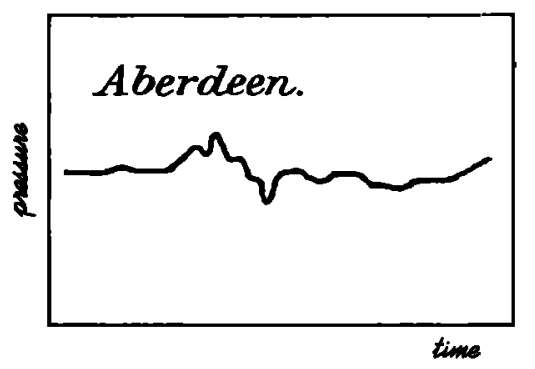

Fig. 10b. (N wave recorded by a barograph at Aberdeen, Scotland, from the eruption of Krakatoa in 1883 [Strachey, 1888]). Neither the time scale nor the amplitude of the trace is given in the cited reference: we estimate that the duration of the $\mathrm{N}$ wave may be as long as several minutes.

chey, 1888] and is frequently demonstrated by the sonic boom from aircraft, after the wave propagates some distance from the source in spherical symmetry, the pressure behind the front falls below atmospheric. A trailing compression is then required to bring the pressure back to ambient. When fluiddynamic nonlinearity and shock steepening are important, the pressure history in the acoustic far field acquires the shape of the letter $\mathrm{N}$, the so-called $\mathrm{N}$ wave. Figure $10 a$ shows the response of a microphone situated a large distance from a transient jet in the present experiments. Several well-formed Nshaped atmospheric waves were observed far from the event at Krakatoa (Figure 10b; Strachey [1888]). The extent of nonlinearity and absence of dispersion of these acoustic gravity waves suggested by the waveforms is remarkable.

\subsection{Steady State Jet Structure}

Our experiments show that, at any distance from the reservoir exit, steady flow features develop almost immediately after passage of the flow head (cf. especially Figure 5a). Furthermore, even for the shortest reservoir $(2.5 \mathrm{~cm})$, which exhausts most rapidly, flows develop that are qualitatively very similar to steady flows at equivalent conditions. Except for brief eruptions in which most of the mass is ejected in the flow head itself, a steady flow model based on contemporaneous reservoir conditions gives a valid picture of conditions in the jet after passage of the starting vortex. A qualitative illustration of the structure of a steady supersonic jet is given in Figure 11 for comparison with the laboratory photographs.

In general, details of the jet structure, including divergence angle, curvature of the external boundary, distance to the Mach disk shock, and diameter of the Mach disk, depend on the thermodynamic properties of the fluid, the ratio of reservoir to ambient pressures, and the ratio of exit to throat area (1.07, cf. Figure $2 a$, which shows how the blockage by the knife blades causes the effective throat area to be less than the exit area). The lateral divergence of the jet at the orifice is calculated as the difference between the Prandtl-Meyer angle lor flow from $P_{4}$, to $P_{a}$ and the Prandtl-Meyer angle for the exit Mach number $M_{e}$. For all gases we estimate the exit Mach number as 1.3. The calculated lateral divergence is then $14^{\circ}$ for helium, $18^{\circ}$ for nitrogen, and $26^{\circ}$ and $28^{\circ}$ for Freon 12 and 22 , respectively. These are comparable to, or larger than, the observed angles (see Figures 6 and 7, which show the divergence of nitrogen jets while the reservoir is in state $4^{\prime}$ ).

The rarefactions that deflect the flow laterally at the orifice reflect from the boundary as compressions and coalesce to form so-called "intercepting" or "barrel" shocks. These features are prominent as bright oblique lines in the schlieren 


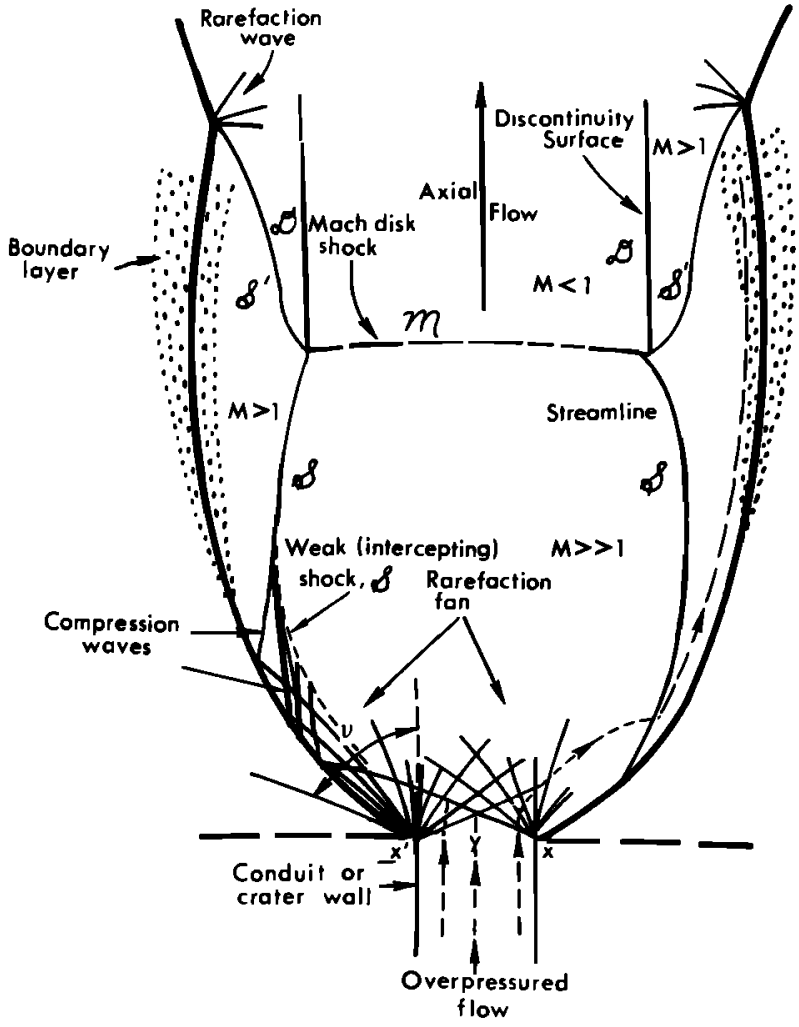

Fig. 11. Schematic illustration of the features in an underexpanded jet [Joint Army, Navy, NASA, Air Force, 1975].

photos (e.g., Figures $6 b$ and $6 d$ ). The barrel shocks are connected across the flow at their downstream end by the Mach disk, and their reflections radiate outward from the Mach disk triple point as oblique shocks. The reflected shocks, in turn, intersect the outer boundary of the flow at its plane of minimum diameter. The entire pattern repeats again and again in the downstream direction (Figure 6d).

\subsection{Decline of the Flow}

As time during the eruption increases, and the reservoir pressure decreases, the Prandtl-Meyer angle decreases, and the diameter and stand-off distance of the Mach disk decrease. In effect, the jet "collapses." These changes are most noticeable when the reservoir pressure decreases to a value for which the flow is everywhere subsonic.

In this section we derive an approximate expression for the decay of reservoir pressure with time and compare it with the experimental results. We use the theory of one-dimensional compressible flow and assume quasi-steady flow. In particular, nonuniformities in the reservoir are neglected. Thus the calculation only applies to reservoir geometries for which the constriction at the exit is rather severe. We further assume that the reservoir pressure is so high that the exit flow is choked and the jet flow is supersonic. In principle, a further calculation should be made of the flow decay after the nozzle unchokes and the flow becomes subsonic, but we apply the results only to large pressure ratio cases, for which the time in supersonic flow is much greater than in subsonic.

The mass flux $\dot{m}$ through the exit plane is

$$
\dot{m}=\rho^{*} c^{*} A
$$

where $\rho^{*}$ and $c^{*}$ are the sonic conditions, assumed constant across the orifice area $A$. The conservation of mass in the reservoir yields

$$
\frac{d \rho}{d t}=-\frac{\dot{m}}{V}=-\rho^{*} c^{*} \frac{A}{V}
$$

where quantities without superscripts refer to reservoir conditions and $V$ is the reservoir volume. Now, from the isentropic flow relations [e.g., Liepmann and Roshko, 1957],

$$
c^{*}=c\left(\frac{2}{\gamma+1}\right)^{1 / 2} \quad \rho^{*}=\rho\left(\frac{2}{\gamma+1}\right)^{1 /(\gamma-1)}
$$

and, from the equation of state for the adiabatic expansion of a perfect gas,

$$
\frac{c}{c_{0}}=\left(\frac{\rho}{\rho_{0}}\right)^{(\gamma-1) / 2}
$$

where subscript 0 refers to initial conditions in the reservoir. Then

$$
\frac{d \rho}{d t}=-\rho_{0} c_{0} \frac{A}{V}\left(\frac{2}{\gamma+1}\right)^{(\gamma+1) / 2(\gamma-1)}\left(\frac{\rho}{\rho_{0}}\right)^{(\gamma+1) / 2}
$$

If $\gamma \neq 1$, this integrates to

$$
t=\left[\left(\frac{\rho}{\rho_{0}}\right)^{(1-\gamma) / 2}-1\right]\left[\left(\frac{2}{\gamma-1}\right)\left(\frac{2}{\gamma+1}\right)^{-(\gamma+1) / 2(\gamma-1)}\right] \frac{V}{c_{0} A}
$$

for $t_{0}=0$. For an adiabatic expansion, this equation alternatively can be written in terms of pressure:

$$
t=\left[\left(\frac{P}{P_{0}}\right)^{(1-\gamma) / 2 \gamma}-1\right]\left[\left(\frac{2}{\gamma-1}\right)\left(\frac{2}{\gamma+1}\right)^{-(\gamma+1) / 2(\gamma-1)}\right] \frac{V}{c_{0} A}
$$

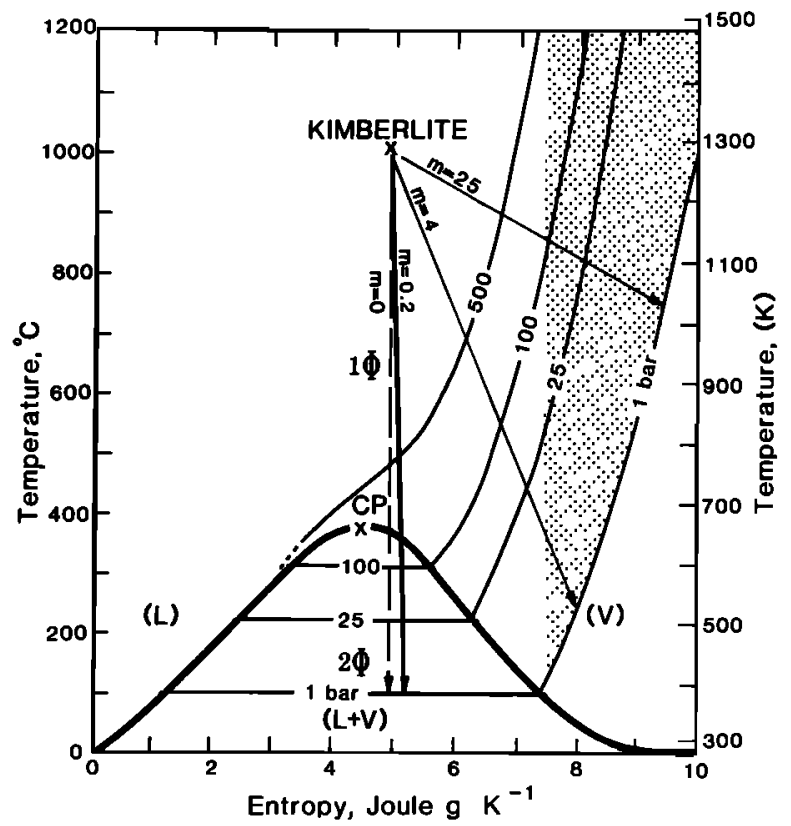

Fig. 12. Temperature-entropy diagram for $\mathrm{H}_{2} \mathrm{O}$. The shaded region on the right shows the range of initial conditions from which isentropic decompression (vertical paths) of pure $\mathrm{H}_{2} \mathrm{O}$ would produce vapor alone. Other initial conditions result in a two-phase mixture either by boiling (if the initial entropy is less than the critical point entropy) or by condensation, as shown by the sample path labeled $\boldsymbol{m}=\mathbf{0}$ from an initial condition appropriate to a kimberlite reservoir. The paths slanted to higher entropy represent the thermodynamic path of the $\mathrm{H}_{2} \mathrm{O}$ component in an adiabatically decompressing mixture of $\mathrm{H}_{2} \mathrm{O}$ and particulate matter. The ratio of particulate mass to $\mathrm{H}_{2} \mathrm{O}$ is denoted by $m$. 
The pressure history calculated from (10) for the experimental configuration, where $V=384 \mathrm{~cm}^{3}$ and $A=1.81 \mathrm{~cm}^{2}$, is shown in Figure $4 b$. The agreement with measurements is satisfactory. The difference between the predicted and measured curves at late time may be due to discharge of about 160 $\mathrm{cm}^{3}$ of vapor in recharge tubing connected to and not isolated from the reservoir.

For the gases studied the transition from a supersonic to a subsonic jet should occur when the reservoir pressure decreases to about 2 times ambient. The structure of weakly supersonic steady jets was studied by Love and Grigsby [1955]. In the present experiments, because the shocks and rarefactions in the jet are so weak and the obscuration of the internal structure by shear layer turbulence is so strong, the waves seem to disappear before the transition to subsonic conditions while the pressure is still about twice the transition pressure. When the reservoir pressure is in the range of 2-4 times atmospheric, the effects of compressibility are less important and, when the jet becomes subsonic, are negligible (Figure 5d).

\section{Discussion}

Though the primary purpose of the present study is to provide a basis for comparison with experiments using multiphase fluids, enough volcanic eruptions resemble these experiments to justify brief discussion of the analogies. The fluids in such eruptions are either gases or behave like pseudogases. Eruptions that produce jets similar to our laboratory jets include phreatic to phreatomagmatic events where pulverized country rock and fragmented magma are driven largely by magmaheated expanding meteoric water vapor and magmatic pyroclastic jets driven largely by exsolved juvenile volatiles. As far as the jet structure is concerned, the origin of the gas is immaterial. Examples might include (1) the Mount Saint Helens phreatic eruptions of March and April 1980; (2) the Vulcanian eruptions of Ngauruhoe, February 1975; (3) the lateral blast at Mount Saint Helens on May 18, 1980 (assuming either that there was substantial hydrothermal contribution to the eruption or that any magmatic volatiles involved had exsolved prior to eruption); and (4) gas-rich, reticulite-forming phases of some Hawaiian eruptions. More speculatively, if the magma involved in large caldera eruptions exsolves its gas prior to eruption, then the large caldera-forming eruptions that result in massive ash flows (e.g., the emplacement of the Bishop Tuff 700,000 years ago in Long Valley, California) may form volcanic jets that act as pseudogases.

TABLE 3. Properties of Various Volcanic Gases and Pseudogases

\begin{tabular}{|c|c|c|c|c|c|c|c|}
\hline \multirow[b]{2}{*}{$m$} & \multicolumn{2}{|c|}{$\gamma$} & \multirow[b]{2}{*}{$\underset{\mathrm{J} / \mathrm{kg} \mathrm{K}}{R,}$} & \multicolumn{2}{|c|}{$c, \mathrm{~m} \mathrm{~s}^{-1}$} & \multirow[b]{2}{*}{$P^{*} / P_{0}$} & \multirow[b]{2}{*}{$c^{*} / c_{0}$} \\
\hline & $\begin{array}{c}\text { at } \\
600^{\circ} \mathrm{C}\end{array}$ & $\begin{array}{c}\text { at } \\
1100^{\circ} \mathrm{C}\end{array}$ & & $\begin{array}{c}\text { at } \\
600^{\circ} \mathrm{C}\end{array}$ & $\begin{array}{c}\text { at } \\
1100^{\circ} \mathrm{C}\end{array}$ & & \\
\hline 0 & 1.26 & 1.22 & 463 & 714 & 895 & 0.55 & 0.94 \\
\hline 1 & 1.16 & 1.14 & 231 & 484 & 607 & 0.57 & 0.96 \\
\hline 2 & 1.12 & 1.10 & 154 & 388 & 486 & 0.58 & 0.97 \\
\hline 5 & 1.06 & 1.06 & 77 & 267 & 335 & 0.59 & 0.98 \\
\hline 10 & 1.03 & 1.03 & 42 & 194 & 243 & 0.59 & 0.99 \\
\hline 25 & 1.02 & 1.01 & 18 & 127 & 159 & 0.60 & 0.99 \\
\hline 50 & 1.01 & 1.01 & 9.1 & 90 & 113 & 0.60 & 0.99 \\
\hline 100 & 1.004 & 1.004 & 4.6 & 63 & 79 & 0.60 & 0.99 \\
\hline 200 & 1.002 & 1.002 & 2.3 & 45 & 56 & 0.60 & 0.99 \\
\hline
\end{tabular}

Here $m$ is the ratio of the mass of solids to the mass of vapor per unit volume.

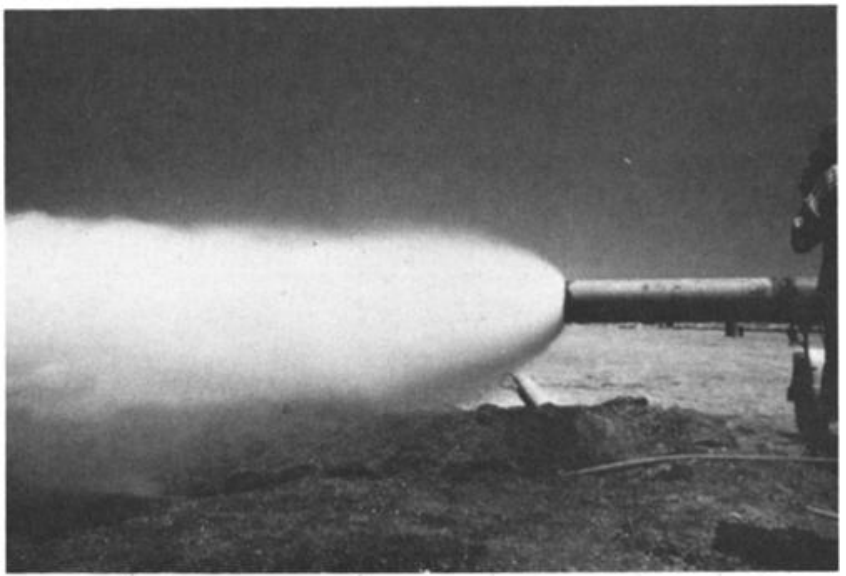

Fig. 13. A geothermal bore discharging in the Imperial Valley. The flow is choked at the pipe exit and produces a supersonic jet with the characteristic flared shape.

There are no volcanic eruptions for which observations permit a well-constrained flow model, even using the simplified pseudogas assumption. The most important of the illconstrained variables are (1) the abundance of volatiles, (2) the geometry of the volcanic system (expressed through $V, A$, and reservoir-nozzle geometry), and (3) initial pressure and temperature in the reservoir (expressed through an average $\boldsymbol{P}_{0}$ and $T_{0}$ ). Thus application to specific volcanoes is limited. The purpose of this section is to point out several phenomena that may be observed and their relation to reservoir conditions.

\subsection{Initial Conditions and Thermodynamic Paths}

The geometry of volcanic systems at depth is rarely known. Field observations suggest that eruptions commonly begin with the propagation of narrow fissures from magma reservoirs to the surface, a configuration that resembles a convergent nozzle above a reservoir (Figure 1a). Repeated eruptions can take place from the same fissure or from a roughly cylindrical conduit that develops within the fissure.

Plausible initial conditions and thermodynamic paths of fluids that might satisfy the requirement that no phase changes occur in the jet flow are shown on the TS diagram of $\mathrm{H}_{2} \mathrm{O}$ in Figure 12. Use of the $T S$ diagram to analyze the behavior of the gaseous component assumes equilibrium thermodynamic conditions throughout the flow. At initial reservoir temperatures of $600-1100^{\circ} \mathrm{C}$ and at pressures up to 1 kbar the fluid remains on the vapor side of the coexistence region, so long as its ascent is either isentropic or the entropy of the vapor increases (by thermodynamic irreversibility or by heat transfer, e.g., from the walls of the conduit or from particulate material entrained in the gas). Volcanic fluids satisfying these requirements range from pure steam to particulate-laden gases of mixed composition $\mathrm{(H}_{2} \mathrm{O}, \mathrm{CO}_{2}, \mathrm{SO}_{2}, \mathrm{H}_{2} \mathrm{~S}, \mathrm{CO}, \mathrm{Cl}$, etc.). For simplicity, we assume that the dominant vapor in particulate-laden jets is $\mathrm{H}_{2} \mathrm{O}$; if the flow is even moderately mass loaded, the composition of the gas is unimportant unless it participates in phase changes, which disqualifies the mixture from a pseudogas treatment anyway. The properties of pure steam and of steam laden with a weight ratio $m$ of solids at 600 and $1100^{\circ} \mathrm{C}$ are shown in Table 3. Note that the ratio of specific heats $\gamma$ of the mixture decreases rapidly from the value for pure steam toward unity, as the mass loading increases from zero to values that are only at the low end of the range encountered in volcanic flows $(m \sim 10)$ and that $\gamma$ is quite 


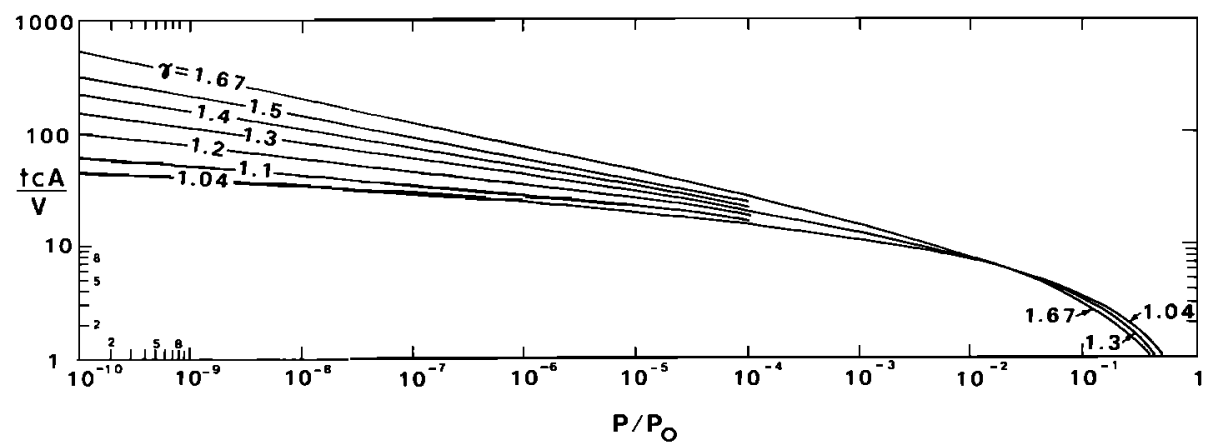

Fig. 14. Pressure decay of the supersonic part of gas or pseudogas eruptions versus normalized time.

independent of temperature. In addition, decrease of the gas constant $\boldsymbol{R}$ with mass loading dramatically affects the reservoir sound speed.

\subsection{Triggering and Development of the Flow}

For explosive eruptions in which the triggering is rapid compared with the duration of the eruption, the flow history should be similar to that shown in Figure 3, providing the axes are properly scaled by the sound speed of the fluid and the dimensions of the volcanic system. As the fluid in the reservoir accelerates from rest toward the vent, its pressure decreases. The pressure drop between reservoir and vent is $0.55-0.60$ for the entire range of pseudogases considered (Table 3). Fluids at initial pressures higher than about 1.8 times atmospheric are overpressured (underexpanded) when they leave the conduit. The sonic velocities for these fluids are within a few percent of the reservoir sound speed $(0.94-0.99 c)$. Depending on temperature and mass loading, choked conduit velocities may range from nearly $900 \mathrm{~m} \mathrm{~s}^{-1}$ for pure steam down to only a few tens or a hundred meters per second for particulate-laden jets.

5.2.1. Unsteady flow at the head. The present experiments demonstrate that velocities in the choked conduit are the highest for low-density gases (e.g., helium) and are lower for dense gases (e.g., Freon). However, the flow head velocities, when normalized by sound speed, show the opposite dependence on density: The helium jet is decelerated most rapidly (presumably by entrainment of relatively heavy ambient air), whereas the Freon jet shows little deceleration. An empirical expression derived from the data presented in section 4.2.1 that relates the head velocity $u_{h}$ a few diameters from the exit to the sound speed $c$ and molecular weight $m$ of the three gases studied to date is approximately

$$
u_{h} \sim c \frac{m / m_{a}}{1 / 3+m / m_{a}}
$$

where unsubscripted quantities refer to reservoir fluid and ()$_{a}$ refers to the atmospheric fluid. Equation (11) expresses the fact that for light gases the head is decelerated much more rapidly than for heavy. The equation does not include any variation of $u_{h}$ in the streamwise (x) direction, a dependence that has not yet been examined with any precision in the present experiments. Further study of flow head velocity is required; field observations should include documentation of observed vent and flow head velocities whenever possible.

5.2.2. Atmospheric shock wave. In view of the dependence of head velocity on flow parameters, volcanic fluids with low mass loading should initially produce the strongest atmospheric compression waves, but the subsequent wave strength may be strongly affected by head deceleration. If the eruption begins with the discharge of relatively gas-rich material, e.g., a steam cap, it will produce a stronger, sharper compressive wave than an explosive event that begins with the discharge of more ash or frothy magma. Because the sound speed of a fluid increases with increasing temperature, hot gases will generate stronger compression waves than cooler ones.

Where atmospheric shocks have been observed upon initiation of a volcanic eruption, the setting has often been such that the occurrence of a volatile-rich "cap" overlying a magma is plausible: at the Vulcanian-style eruptions of Ngauruhoe (New Zealand), Sakurajima (Japan), and at Mount Pelé. In contrast, due to the manner by which the lateral blast at Mount Saint Helens on May 18, 1980, was triggered, a dense mixture was suddenly exposed to the atmosphere, and an atmospheric shock wave was absent. The smooth compression wave generated by the blast steepened by atmospheric refraction into a shock only after it had propagated about $200 \mathrm{~km}$ from the source [Reed, 1980]. Although no audible shock wave was reported near the volcano, an $\mathrm{N}$ wavelike record was obtained at Toledo, $54 \mathrm{~km}$ northwest.

Though not apparent in the photographs presented in this paper, but seen in other photos from these experiments, especially of helium jets at small times, the shape of the atmospheric shock is nonspherical, protruding outward along the jet axis. The portion of the shock that is pushed along the axis by the (decelerating) flow head retains a finite strength longer than the portions that diffract around to the sides of the jet. Thus the laboratory results are in accord with the field observations of Nairn [1976] concerning wave shape.

\subsection{Steady State Jet Structure}

The internal structure of volcanic jets, particularly the steady shock and rarefaction waves that arise when the jet is underexpanded (as described in section 4.3), is difficult to document, both due to the paucity of field observations and because of the opacity of volcanic fluids. Reported internal waves (at Tolbatchik, USSR [Livshits and Bolkhovitinov, 1977]), were not the stationary waves described here, but rather were traveling surge waves attributed to oscillations of exit flow velocities above and below sonic. Actually, conclusive evidence for supersonic flow and internal waves would be the simple observation of substantial jet pluming at the conduit exit, due to Prandtl-Meyer expansion and subsequent inward curvature of the jet boundaries (sections 2.3 and 2.4). Unfortunately, the part of volcanic jets where such effects occur is often deep within a volcanic crater, or is otherwise obscured from observation by volcanic topography or debris. Such boundaries are often prominent on discharges from geo- 
thermal bores (Figure 13), which are sometimes modeled as pseudogas flows.

The high internal pressure that exists in underexpanded jets can erode the conduit (Figure $1 b$ ) into a crater (Figure $1 c$ ) [Kieffer, 1982b]; deposition of ejecta may also modify conduit-crater geometry [Wilson et al., 1980]. The structure of jets emerging from craters will be different from those emerging from simple straight conduits.

\subsection{Duration of Eruptions}

The results of the calculation of reservoir discharge (10) exhibit the variables that influence reservoir pressure decay under conditions for which all the simplifying assumptions of the model apply; that is, for high reservoir pressures and for reservoir geometries in which the exit constriction is severe, so the flow is quasi-steady and supersonic. The variables controlling the discharge are the gas properties through $\gamma$ and the equation of state, the initial reservoir conditions through the sound speed $c$, and the volume to area ratio $V / A$. The pressure decay scales linearly with a characteristic time, $\tau=V /\left(A c_{0}\right)$, as shown by the dimensions of (5). The duration of an eruption can be approximated by the time that it takes the reservoir to discharge to the pressure $P_{f}$ that yields ambient pressure $\boldsymbol{P}_{a}$ in the sonic throat. Eruption durations defined in this way scale with $\tau$. The $\tau$ is also the characteristic time for the discharge of a cylindrical reservoir with no exit constriction, which according to one-dimensional shock tube theory, is dominated by nonsteady wave processes and for which $V / A=L$, the tube length. Thus reservoirs modeled as very long cylinders ("cylinder models") or reservoirs modeled as large volumes with small exits ("pinhole models") both have very large $V / A$ and long durations.

Calculated results from (10) for a range of volcanic conditions and for low- $\gamma$ fluids are shown in Figure 14. For a few eruptions where adequate data are available, the model seems to give reasonable relations between $t, A / V$, and $P$. As an example, a cylindrical terrestrial steam reservoir $(V / A=L)$ $500 \mathrm{~m}$ long initially at $180 \mathrm{bar}, 600^{\circ} \mathrm{C}$ would discharge supersonically until the pressure dropped to $1.8 \mathrm{bar}$, i.e., to $P_{S} /$ $P_{0}=0.010$. The discharge time would be $5 \mathrm{~s}$. If it were a pseudogas with $m=100$ and $\gamma=1.004$ (Table 3), subsonic conditions would be reached when $P_{f}=1.7$ bars or when $P_{f} / P_{0}=0.0094$. The discharge time would be $60 \mathrm{~s}$. Durations of 5-60 $\mathrm{s}$ are typical of the durations of phreatic or phreatomagmatic bursts when the discharge approximates that of a pseudogas from a reservoir; the Ngauruhoe eruptions of 1974 and 1975 consisted of bursts of tens of seconds duration [Nairn, 1976], and the duration of the lateral blast at Mount Saint Helens on May 18, 1980, was similar [Kieffer, 1982a]. For discharge to ambient conditions on $I 0\left(P_{f} / P_{0} \sim 10^{-10}\right)$, the duration would be about $50 \mathrm{~s}$ for the pure steam example and about $5 \mathrm{~min}$ for the pseudogas example.

Terrestrial reservoirs that are simple cylindrical conduits ranging up to a few kilometers in length will, if they contain gaslike fluids, be emptied in a few hundred seconds. Deviations from simple cylindrical geometry that give very large volume to area ratios $(V / A)$ could significantly increase this time. A gas-rich eruption would be about 1 order of magnitude longer if it occured on Io, where the ambient atmospheric pressure is $10^{-7}-10^{-12}$ that of earth. Gassy volcanic eruptions that last more than a few hours (for example, virtually all large pyroclastic events on the earth and the long eruptions on Io) indicate either that the erupting reservoirs are open to recharge (e.g., resemble continuously discharging fu- meroles) or that the discharge is from a finite reservoir but the fluids do not behave as gases or pseudogases for the duration of the eruption (e.g., the discharge of fluids initially liquid when the eruption begins is controlled by the saturation curve). Since many terrestrial eruptions similarly involve saturated liquids, future experiments should examine such cases. The results of the present study cannot be extrapolated to eruptions in which changes of phase control the flow field.

\section{ApPendix: Pressures in the Reservoir}

We present here the equations for the first few steps of the sequence of steady flow conditions that exist in the reservoir during its discharge. We use the geometry and notation of Figure 3. The expansion of the reservoir fluid behind the shock can be approximated as the following two-step process: (1) an unsteady, constant area expansion through the rarefaction waves, and (2) a steady expansion through the area contraction to sonic conditions.

Since the flow is assumed isentropic, all thermodynamic variables can be expressed in terms of the sound speed. The sound speed is obtained from the appropriate Riemann invariant; for example, for the first rarefaction wave propagating downward and expanding the flow from state (4) to state (4'),

$$
c_{4}=c_{4^{\prime}}+\frac{\gamma-1}{2} \mu_{4}
$$

The pressure in terms of the sound speed is

$$
\frac{P_{4}}{P_{4}}=\left(\frac{c_{4}^{\prime}}{c_{4}}\right)^{2 \gamma /(\gamma-1)}
$$

Thus the pressure ratio in terms of the Mach number in region $\left(4^{\prime}\right)$ is

$$
\frac{\boldsymbol{P}_{4}}{\boldsymbol{P}_{4^{\prime}}}=\left(1+\frac{\gamma-1}{2} M_{4^{\prime}}\right)^{2 \gamma /(\gamma-1)} \sim 1+\gamma M_{4^{\prime}}
$$

where the approximation is valid for small $M_{4}$. The density and temperature may be obtained from (A3) and the equation of state,

$$
\begin{aligned}
\frac{\rho_{4^{\prime}}}{\rho_{4}} & =\left(\frac{P_{4^{\prime}}}{P_{4}}\right)^{1 / \gamma} \\
\frac{T_{4^{\prime}}}{T_{4}} & =\left(\frac{P_{4^{\prime}}}{P_{4}}\right)^{\gamma-1 / \gamma}
\end{aligned}
$$

$M_{4}$, is as yet unspecified. It is determined by the fact that, for sonic conditions at the throat, there is a unique upstream Mach number $M_{4}$, for a given area ratio $A_{r} / A_{e}$ from the reservoir to the exit. When the flow is sonic at the throat (that is, when $M_{4}{ }^{*}=1.0$ and $A_{e} \equiv A^{*}$ ), it is termed "choked." Thus $M_{4}$, is given implicitly by the area Mach number relation,

$$
\frac{A_{r}}{A^{*}}=\frac{1}{M_{4}}\left(\frac{2}{\gamma+1}+\frac{\gamma-1}{\gamma+1} M_{4^{\prime}}{ }^{2}\right)^{(\gamma+1) / 2(\gamma-1)}
$$

It is convenient to construct perfect gas tables for the gases of interest and then to obtain values of $M_{4}$, and the sonic conditions (*) directly from the tables.

The rarefaction $R$, travels down the reservoir until it hits and reflects from the bottom wall as $\boldsymbol{R}_{2}$. In state 5 after the reflection the fluid is at rest; $u_{5}=0$. Using now the Riemann invariant for the opposite family of waves than was the case 
for (A1), we derive the analog of (A3):

$$
\frac{P_{5}}{P_{4^{\prime}}}=\left(1-\frac{\gamma-1}{2} M_{4^{\prime}}\right)^{2 \gamma /(\gamma-1)}
$$

The rarefaction wave $R_{2}$ now reflects from the area change as $R_{3}$. This process is exactly analogous to the $4-4^{\prime}$ transition, so

$$
\frac{P_{5}}{P_{6}}=\left(1+\frac{\gamma-1}{2} M_{6}\right)^{2 \gamma /(\gamma-1)}
$$

where $M_{6}=M_{4}$. Then, $P_{6} / P_{4}$ may be calculated from

$$
\frac{P_{6}}{P_{5}}=\frac{P_{6}}{P_{5}} \frac{P_{5}}{P_{4}} \frac{P_{4}}{P_{4}}
$$

and (A3), (A6), and (A7). The values of flow variables in states $1,4,4^{\prime}, 4^{\prime *}, 5$, and 6 are given in Table 2 for $\mathrm{He}, \mathrm{N}_{2}$, Freon 12 , and Freon 22 initially at $P_{4}=7.25$ bars, $T_{4}=300 \mathrm{~K}$.

Acknowledgment. This work was supported jointly by the National Science Foundation under grant EAR-8218445 and the U.S. Geological Survey. Approved by Director, U.S. Geological Survey, November 10,1983 .

\section{REFERENCES}

Bennett, F. D., Vaporization waves in explosive volcanism, Nature, 234, 538, 1971.

Bennett, F. D., On volcanic ash formation, Am. J. Sci., 274(6), 648$661,1974$.

Chen, C. J., and W. Rodi, Vertical Turbulent Buoyant Jets, Pergamon, New York, 1980.

Eichelberger, J. C., and D. B. Hayes, Magmatic model for the Mount St. Helens blast of May 18, 1980, J. Geophys. Res., 87, 7727-7738, 1982.

El-Kaissey, M. M., and G. M. Homsy, Instability waves and the origin of bubbles in fluidized beds, Int. J. Multiphase Flow, 2, 379$395,1976$.

Hirschfelder, J. O., C. F. Curtiss, and R. B. Bird, Molecular Theory of Gases and Liquids, John Wiley, New York, 1954.

Joint Army, Navy, NASA, Air Force (JANNAF), Handbook of rocket exhaust plume technology, Publ. 263, chap. 2, 237 pp., Chemical Propulsion Information Agency, Washington, D. C., 1975.

Kieffer, S. W., Sound speed in liquid-gas mixtures: Water-air and water steam, J. Geophys. Res., 82, 2895-2904, 1977.

Kieffer, S. W., Fluid dynamics of the May 18 blast at Mount St. Helens, U.S. Geol. Surv. Prof. Pap., 1250, 379-400, $1982 a$.

Kieffer, S. W., Fluid dynamics and thermodynamics of Ionian volcanism, chap. 18, in The Satellites of Jupiter, edited by D. Morrison, pp. 647-723, University of Arizona Press, Tucson, $1982 b$.

Liepmann, H. W., and A. Roshko, The Elements of Gasdynamics, John Wiley, New York, 1957.

Livshits, L. D., and L. G. Bolkhovitinov, Weak shock waves in the eruption column, Nature, 267, 420-421, 1977.

Love, E. S., and C. E. Grigsby, Some studies of axisymmetric free jets exhausting from sonic and supersonic nozzles into still air and into supersonic streams, NACA RM L54L31, 178 pp., Natl. Advisory Comm. on Aeronaut., Washington, D. C., 1955.

Marble, F. E., Dynamics of a gas containing small solid particles, in Proceedings of the Fifth AGARD Combustion and Propulsion Colloquium, pp. 175-213, Pergamon, New York, 1963.

Marble, F. E., Dynamics of dusty gases, Ann. Rev. Fluid Mech., 2, $397-446,1970$.

McGetchin, T. R., The Moses Rockdike: Geology, petrology and mode of emplacement of a kimberlite-bearing breccia-dike, San
Juan County, Utah, Ph.D. thesis, Calif. Inst. of Technol., Pasadena, 1968.

McGetchin, T. R., and G. W. Ulrich, Xenoliths in maars and diatremes with inferences for the Moon, Mars, and Venus, J. Geophys. Res., 78, 1833-1853, 1973.

Nairn, I. A., Atmospheric shock waves and condensation clouds from Ngauruhoe explosive eruptions, Nature, 259, 190-192, 1976.

Reed, J. W., Air pressure waves from Mount St. Helens eruptions (abstract), Eos Trans. $A G U, 6 I(46), 1136,1980$.

Reynolds, A. J., Observations of a liquid-into-liquid jet, $J$. Fluid Mech., 14, 552-556, 1962.

Ricou, F. P., and D. B. Spaulding, Measurements of entrainment by axisymmetrical turbulent jets, J. Fluid Mech., 11, 21, 1961.

Rowe, P. N., Experimental properties of bubbles, in Fluidization, edited by J. F. Davidson and D. Harrison, Academic, New York, 1971.

Rudinger, G., Some effects of finite particle volume on the dynamics of gas-particle mixtures, $A I A A J_{\text {., }}$ 3, 1217-1222, 1965.

Self, S., L. Wilson, and I. A. Nairn, Vulcanian eruption mechanisms, Nature, 277, 440-443, 1979.

Shoemaker, T. R., C. H. Roach, and F. M. Byers, Jr., Diatremes and uranium deposits in the Hopi Buttes, Arizona, in Petrologic Studies, a Volume to Honor A. F. Buddington, pp. 327-355, Geological Society of America, Boulder, Colo., 1962.

Sparks, R. S. J., and L. Wilson, Explosive volcanic eruptions, V, Observations of plume dynamics during the 1979 Soufriere eruption, St. Vincent, Geophys. J. R. Astron. Soc., 69, 551-570, 1982.

Strachey, R., On the air waves and sounds caused by the eruption of Krakatoa in August 1883, in The Eruption of Krakatoa and Subsequent Phenomena: Report of the Krakatoa Committee of the Royal Society, edited by G. J. Symons, Trubner, London, 1888.

Tennekes, H., and J. L. Lumely, $A$ First Course in Turbulence, MIT Press, Cambridge, Mass., 1972.

Thompson, P. A., Compressible-Fluid Dynamics, McGraw-Hill, New York, 1972.

Tombach, I. H., Velocity measurements with a new probe in inhomogeneous turbulent jets, Ph.D. thesis, Calif. Inst. of Technol., Pasadena, 1969.

Townsend, A. A., The Structure of Turbulent Shear Flow, Cambridge University Press, New York, 1976.

Turner, J. F., Buoyancy Effects in Fluids, Cambridge University Press, New York, 1973.

Wilson, L., Explosive volcanic eruptions, III, Plinian eruption columns, Geophys. J. R. Astron. Soc., 45, 543-556, 1976.

Wilson, L., Relationships between pressure, volatile content and ejecta velocity in three types of volcanic explosion, J. Volcanol. Geotherm. Res., 8, 297-313, 1980.

Wilson, L., and J. W. Head III, Ascent and eruption of basaltic magma on the earth and moon, J. Geophys. Res., 86, 2971-3001, 1981.

Wilson, L., R. S. J. Sparks, and G. P. L. Walker, Explosive volcanic eruptions, IV, The control of magma properties and conduit geometry on eruption column behavior, Geophys. J. R. Astron. Soc., 63, $117-148,1980$.

Wohletz, K. H., and R. G. McQueen, Experimental studies of hydromagmatic volcanism, in Explosive Volcanism: Inception, Evolution, and Hazards, edited by F. R. Boyd, pp. 158-169, Geophysics Study Committee, National Academy Press, Washington, D. C., 1983.

S. W. Kieffer, U.S. Geological Survey, Branch of Igneous and Geothermal Processes, 2255 North Gemini Drive, Flagstaff, AZ 86001.

B. Sturtevant, Graduate Aeronautical Laboratories, California Institute of Technology, Pasadena, CA 91125.

(Received November 29, 1983;

revised February 3, 1984; accepted March 1, 1984.) 